


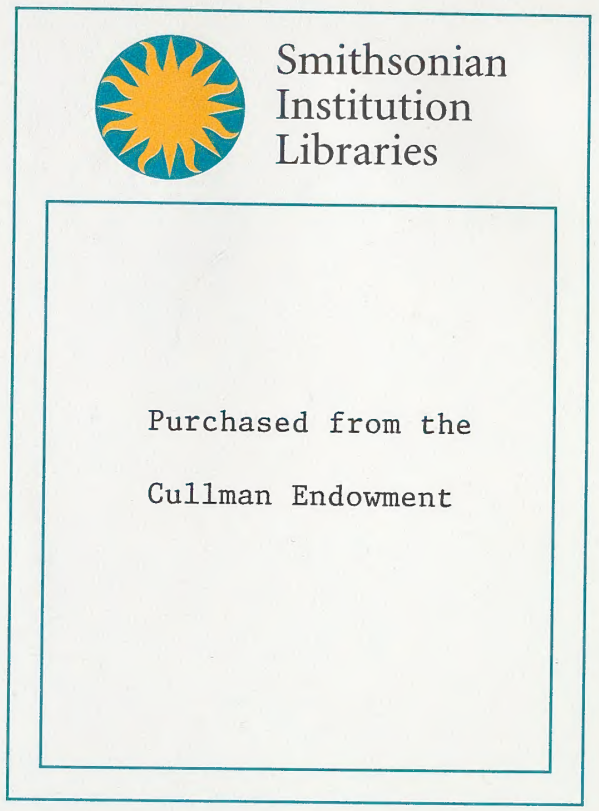






\title{
I cones
}

\section{P i s c i u m.}

\section{Indicem systematicum}

\author{
addidit
}

\section{IF. C. Hielsen,}

qvondam in schola metropolitana magister primarius.

\section{Hafniae 1835.}

Sumptibus Christiani Steen, bibliopolae et chartopratis hafniensis; typis Bianco Luno of Schneider. 
Qvoad Piscium ordines celeberrimum Blumenbach; qroad vero genera speciesqve immortalem Linnaeum (editionem XIIIam ejus Systematis Naturae compara) sumus secuti. Species, parenthesi inclusae, in Systemate Linn. desiderantur; qvare eas servavimus, qvibus usus est auctor in textu danico, aeneas hujus operis tabulas illustraturo. Has etiam adjecimus, ubi differunt a Linneanis.

In hoc indice Branchiostegum coecum Blumenb. (Myxine glutinosam Linn) qridem commemoravimus; sed tabula citata pertinet ad volumen operis hujus, qvod vermes complectitur, inter qros Linnaeus posuerat. 


\section{Classis IV. isces.}

\section{Ordo I. Chondropterygii.}

1. Petromyzon marinus

Tab. Fig.

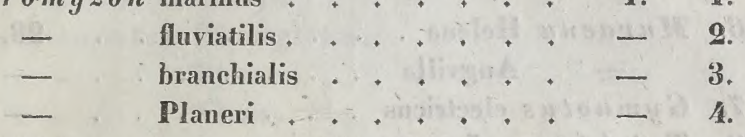

2. Gastrobranchus coecus B1. (Myxine gluti-

5. Raja Torpedo . . . . . . . 1. 5 .

$$
\text { nosa L.) } \left.\quad \text { 61. 1. }{ }^{*}\right)
$$

Batis . + . . . + 23.1 .2$.

— Oxyrhinchus ......... $\quad . \quad 4.5$.

- rubus . . . . . . . 24.4.

- Aqvila ... . . . . . . $\quad 1.2$

- Pastinaca . . . . . . . 23. 3.

- elavata . . . . . . . 24. 3.

4. Squalus Zygaena + . . . . . 2. 3.

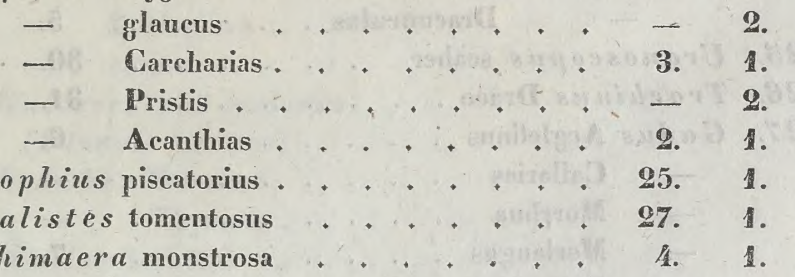

\section{Ordo 耳. Branchiostegi.}

8. Acipenser Sturio

A. 2.

Rhutenus . . . . 3.

Huso,$+\ldots+, \ldots$

9. Ostracion triqueter . . . . . 25. 2. cornutus . . . . . . 3.

10. Tetrodon lagocephalus _. . . . 26. hispidus + + + +.. $+\mathbf{2}$ Mola . . + . . . - 3.

11. Diodon Hystrix . . . . . . . . . 27. 2.

12. Cyclopterus Lumpus .......18. =

*) Vol. 6. Vermes. 
15. Centriscus Scolopax

14. Syngnatus

19. 1.

27. 3.

19.2.

15. Pegasus Draconis

\section{Ordo III. Apodes.}

16. Muraena Helena... . . .

28. 1.

Anguilla ........ - $\quad$ - 2.

17. Gymnotus electricus ........ - 3 . 3

18. Trichiurus Lepturus . . . . . 29.1.

19. Anarrhicas Lupus . . . + . - 2

20. Ammodytes Tobianus ........ - 3.

21. Ophidium barbatum ........ - 4.

go. Stromateus Paru ......... 30. 1.

95. Kiphias Gladius ....... - .

Ordo IV. Jugulares.

24. Callionymus Lyra .......

5. 2.

5. 3.

פ5. Uranoscopus scaber . . . . . . 30. 3.

26. Trachinus Draco . . ...... 31. 1.

27. Gadus Acglefinus . ......... 6. 1 .

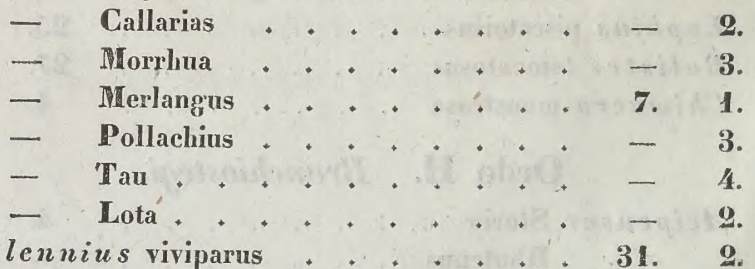

Ordo V. Thoracici.

99. Cepola Taenia

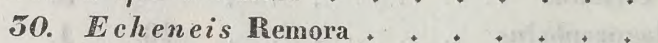

32. 1 .

31. 3.

51. Coryphaena Hippurus

32. 2.

Plumieri

8. 1.

50. Gobius niger. . . + . . + 32. 3.

55. Cottus cataphractus . . . . . . 33. 1 .

Scorpius +.+. +. + 11. I. 
55. Zeus Vomer

56. Pleuronectes Hippoglossus

36. 1.

Platessa . . . . . 35. 1.

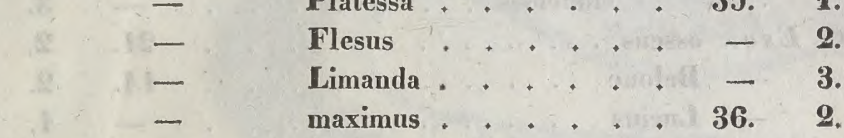

57. Chactodon rostratus . . . . . . 10. 1.

\begin{tabular}{|c|c|}
\hline & macrolepidotus \\
\hline & bicolor . . \\
\hline & marginatus \\
\hline
\end{tabular}

58. Sparus aurata . . . . . . 38. 1.

59. Labrus Julis . . . . . . . 37. 2.

40. Perca fluviatilis . . . . . . 39. 1.

- Lucioperea . . . . . . . . - 2.

- cernua .......... - 3.

11. Gasterosteus aculeatus...... . 40. 1.

41A. (Pterois volitans) . . . . . 48. 1.

19. Scomber Scomber. . . . . . 11. 2.

Thynnus. . . . . 10.2

44. Trigla Lyra . + . . . . + + . + 20.3.

Hirundo . . . . . . . - 1.

- (punctata) ....... . . 4 .

— volitans........ . . 2.

Ordo VI. Abdominales.

45. Cobitis Anableps . . + . . + + . 40. 1 .

Barbatula . . . . . . - 2.

- fossilis . . . . . . . 3 .

46. Silurus Glanis. . . . . . . . 43. 1.

16A. Teuthis IIepatus. . . . . . . 48. 2.

47. Loricaria cataphracta . . . . . . 43. - 2.

plecostomus '. . . . . $12 . \quad 1$. 
48. Salmo Salar

Tab. Fig.

12. 2 .

Trutta

3.

Fario.

13.

- alpinus

g.

- Eperlanus

44.

1.

- Lavaretus

13.

3.

Thymallus

14.

2.

49. Fistularia tabacaria

21.

1.

50. Es o $x$ osseus chinensis .....+, +.+ - 3 .

- Belone 21. 2

\section{- Lucius}

14. 2 .

31. Elops Saurus

ร2. Atherina Hepsetus ..., ..... + - 2.

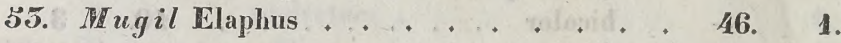

54. Exocoetus volans ... . . . - 2.

зૅљ. Polynemus quinqvarius .......... 48. 3.

ङ6. Clupea Harengus ..........,.. 15. 1.

Sprattus +........

- Alosa ...........4. 47. 1.

- Encrasicolus ......... - 2

57. Cyprinus Barbus ........... 22. 2.

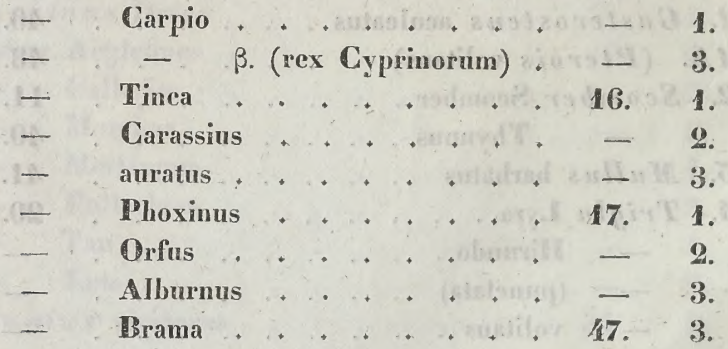


PR.I.
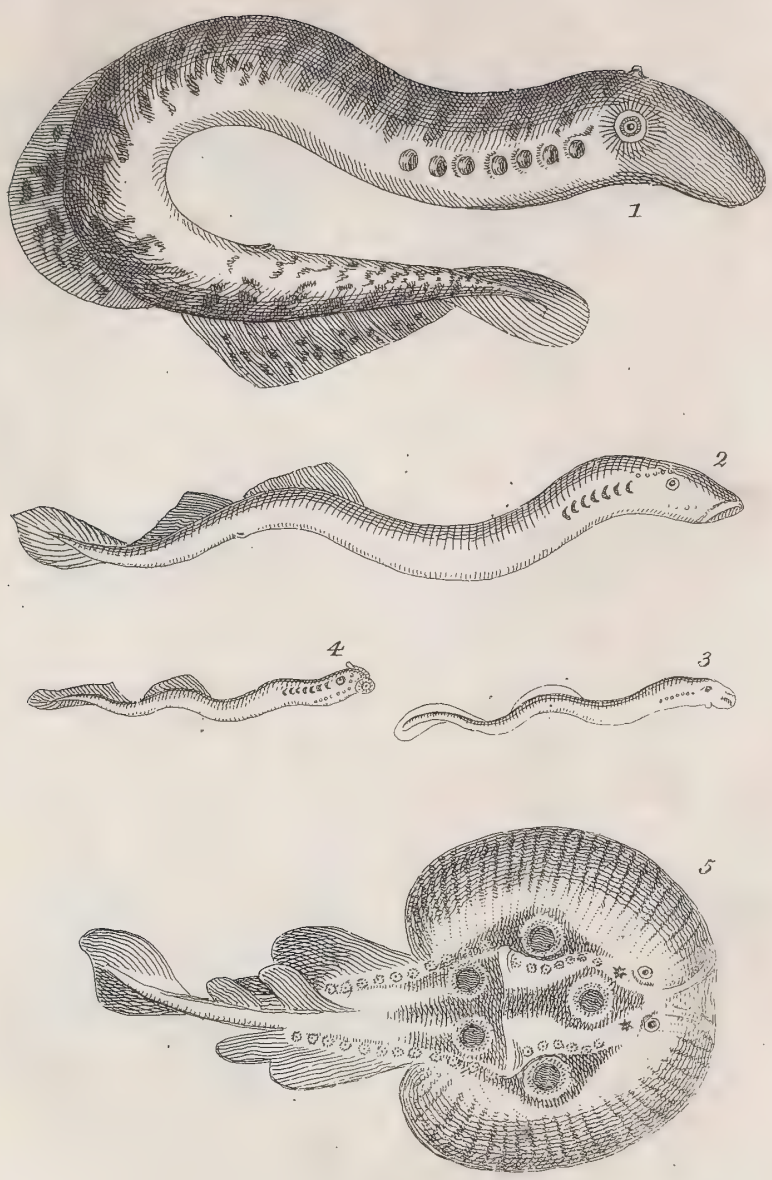


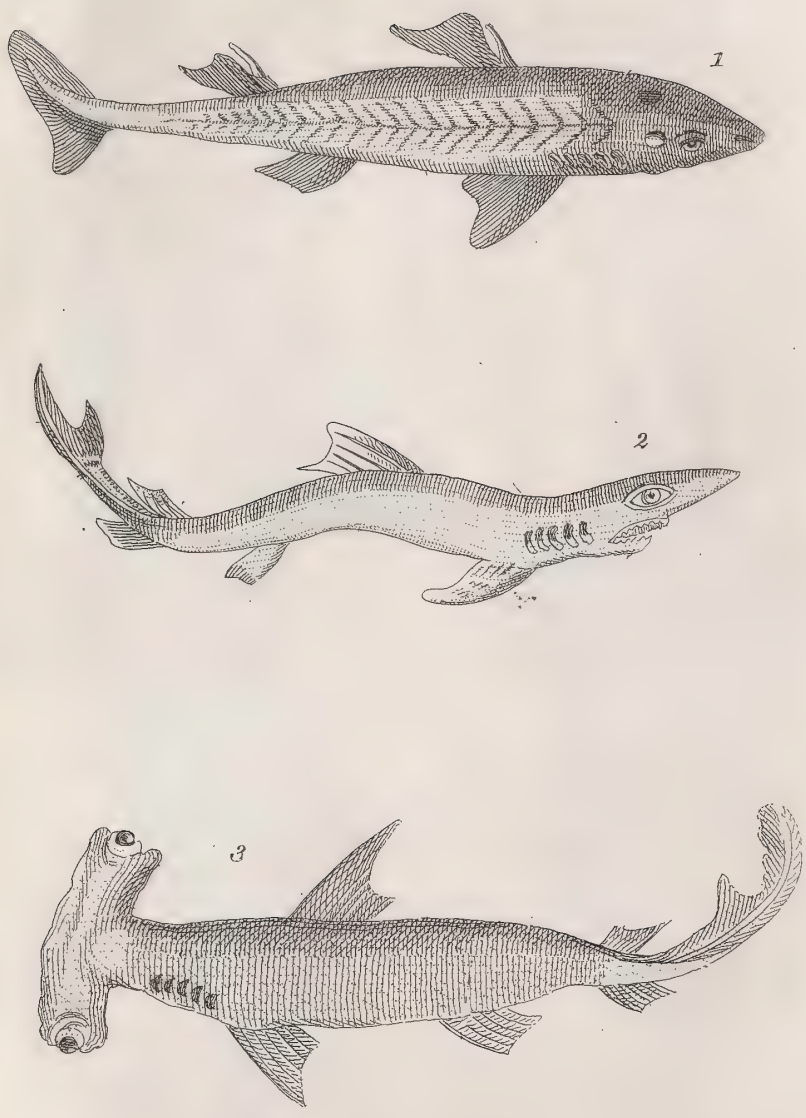



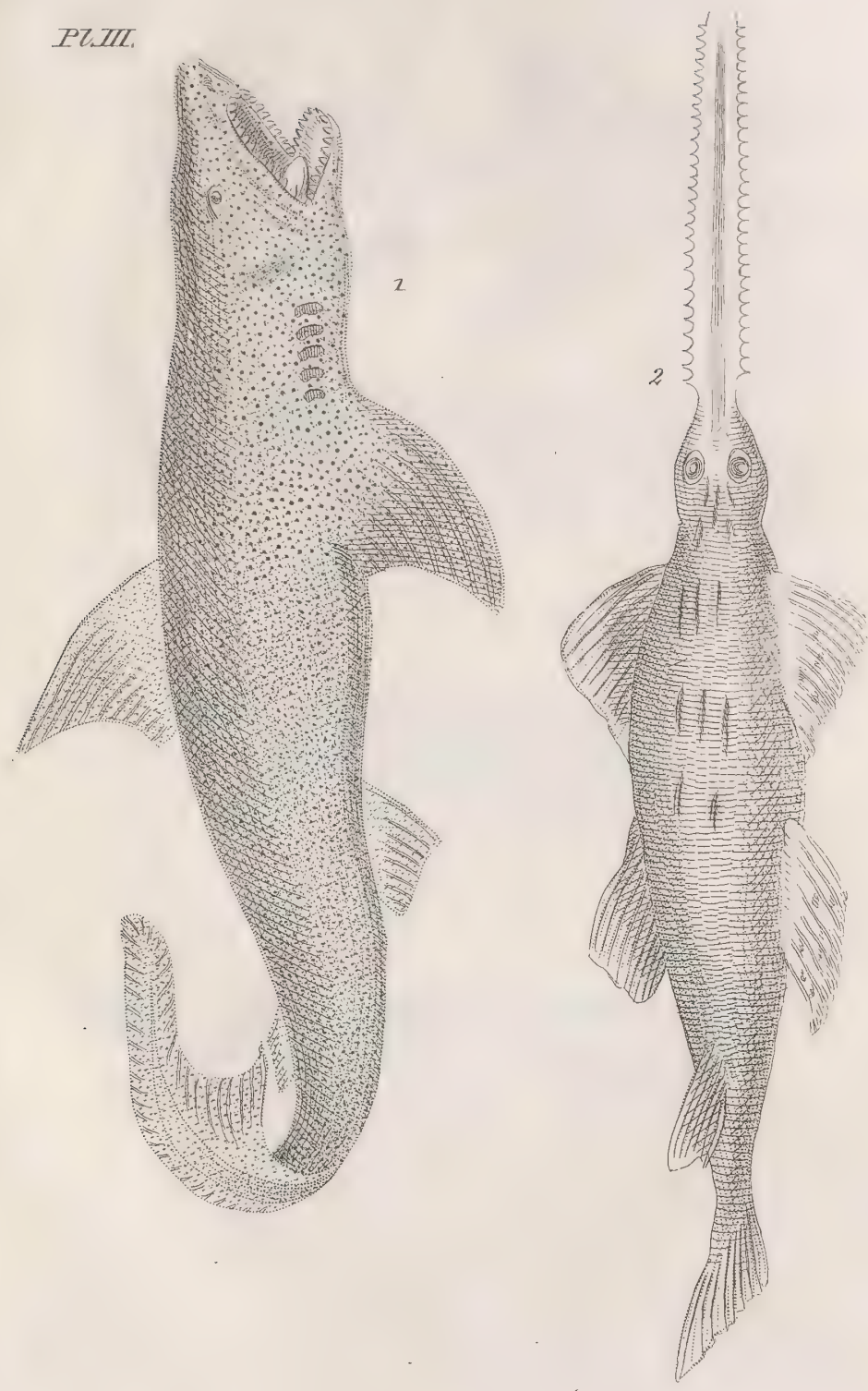




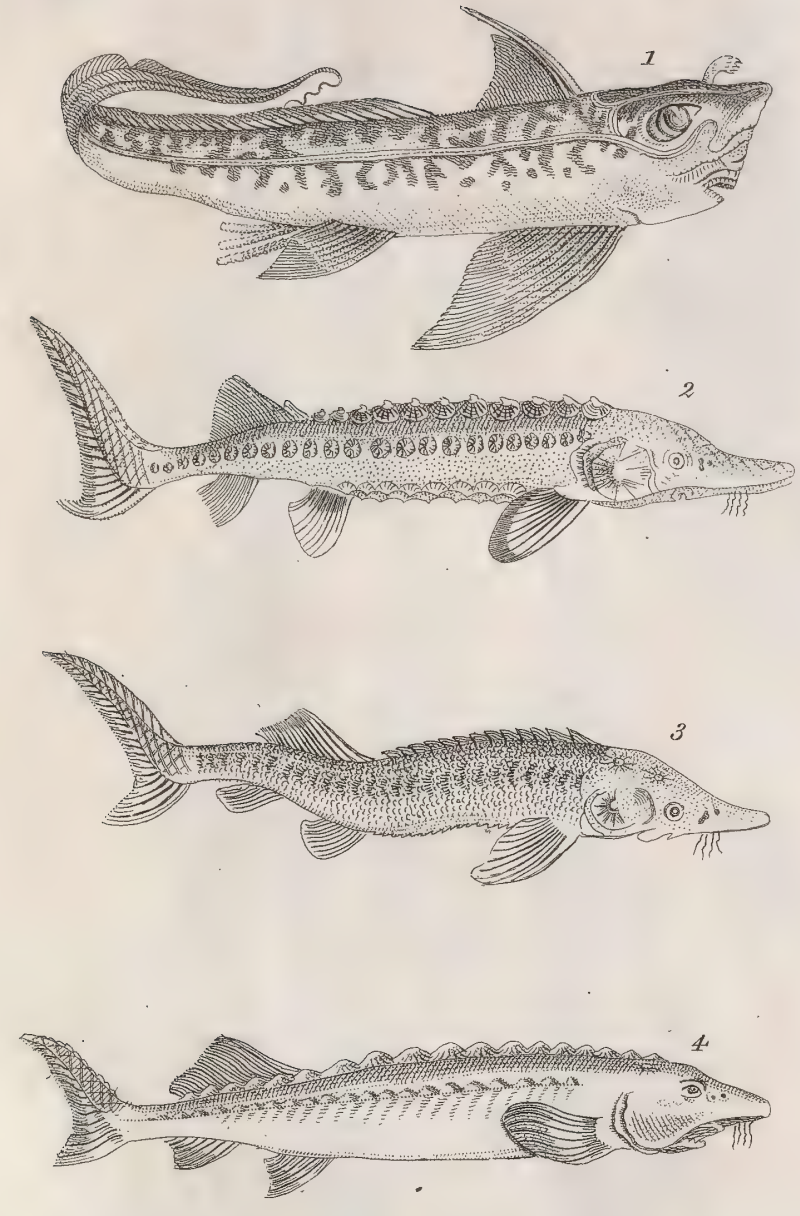


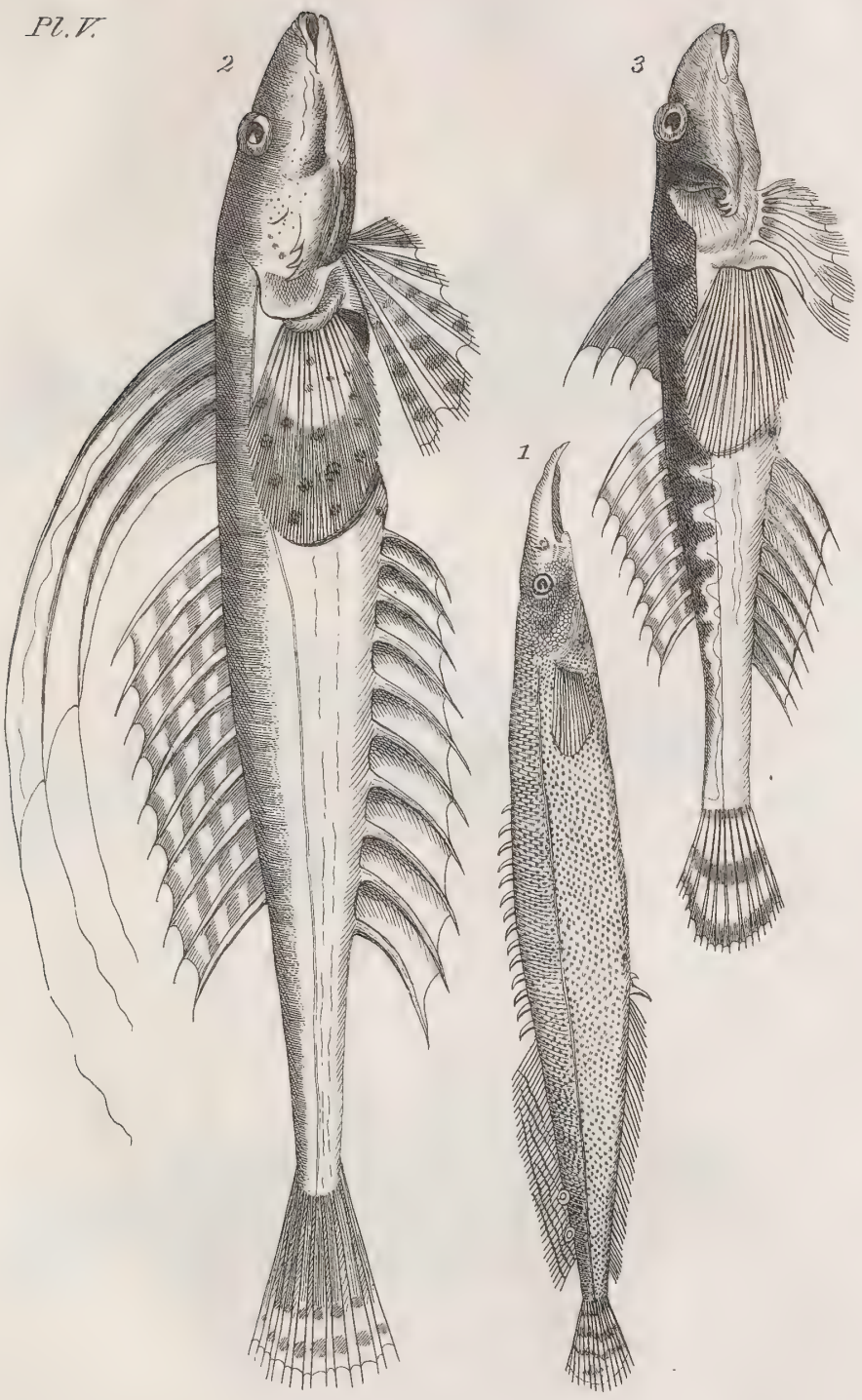

MIVI.
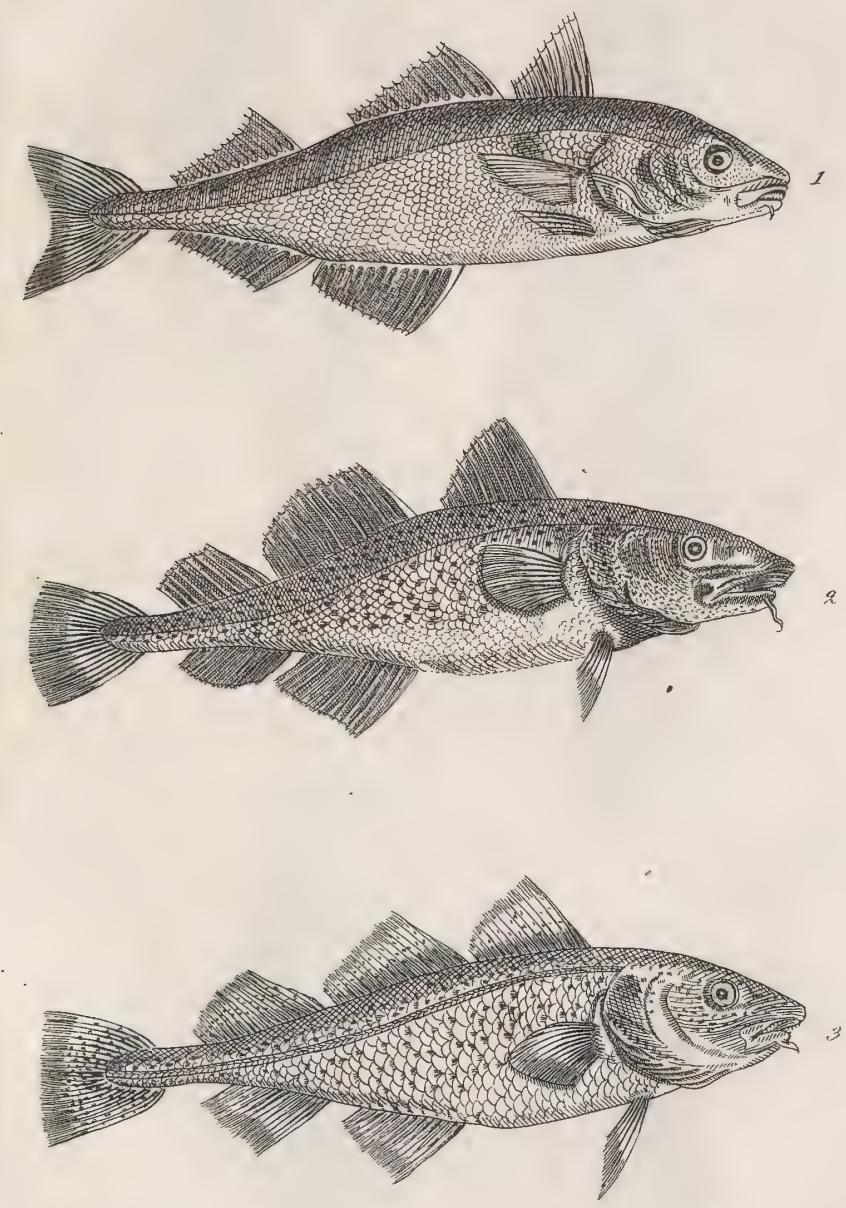

Pl.TII.
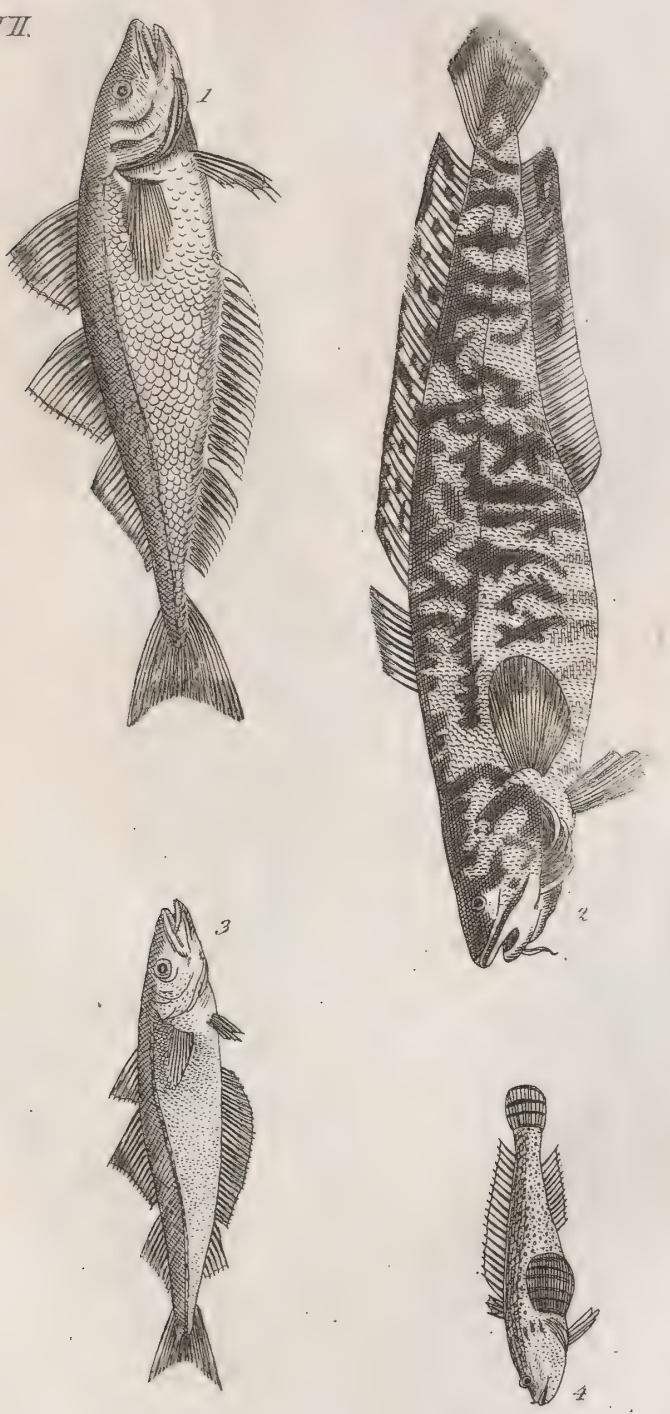

PL.TIII.
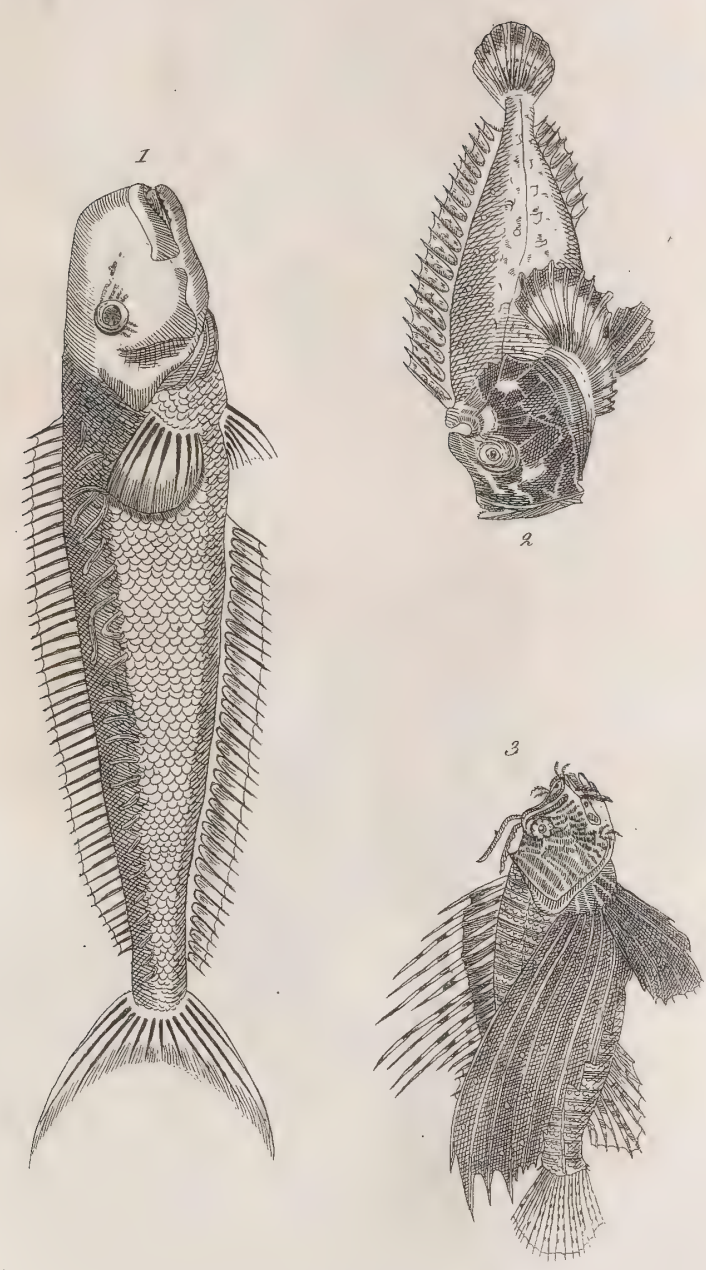

Il. $I X$.
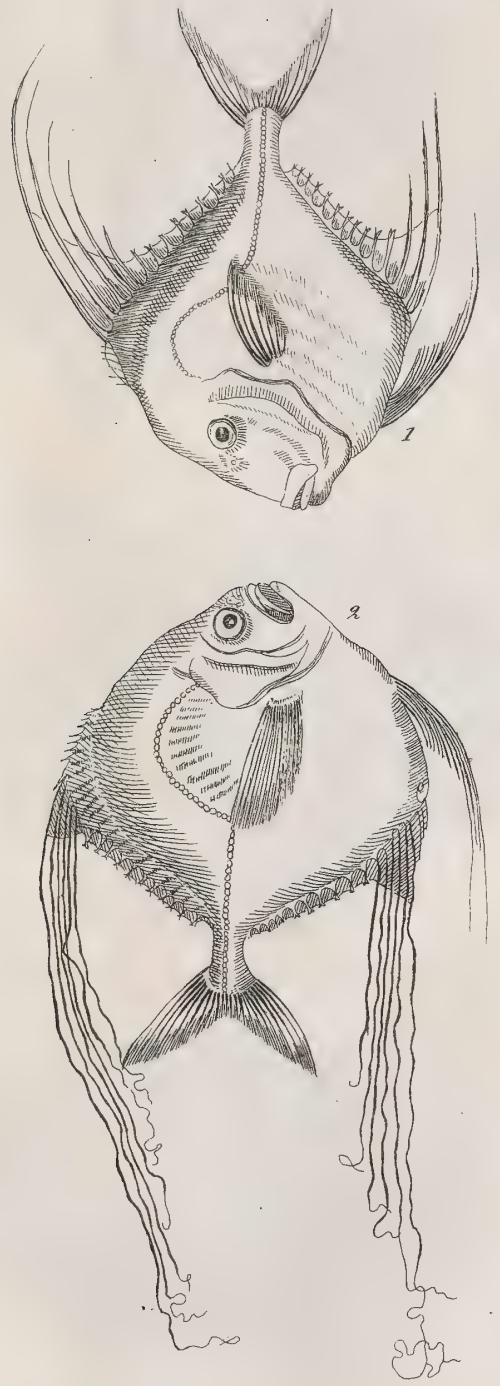


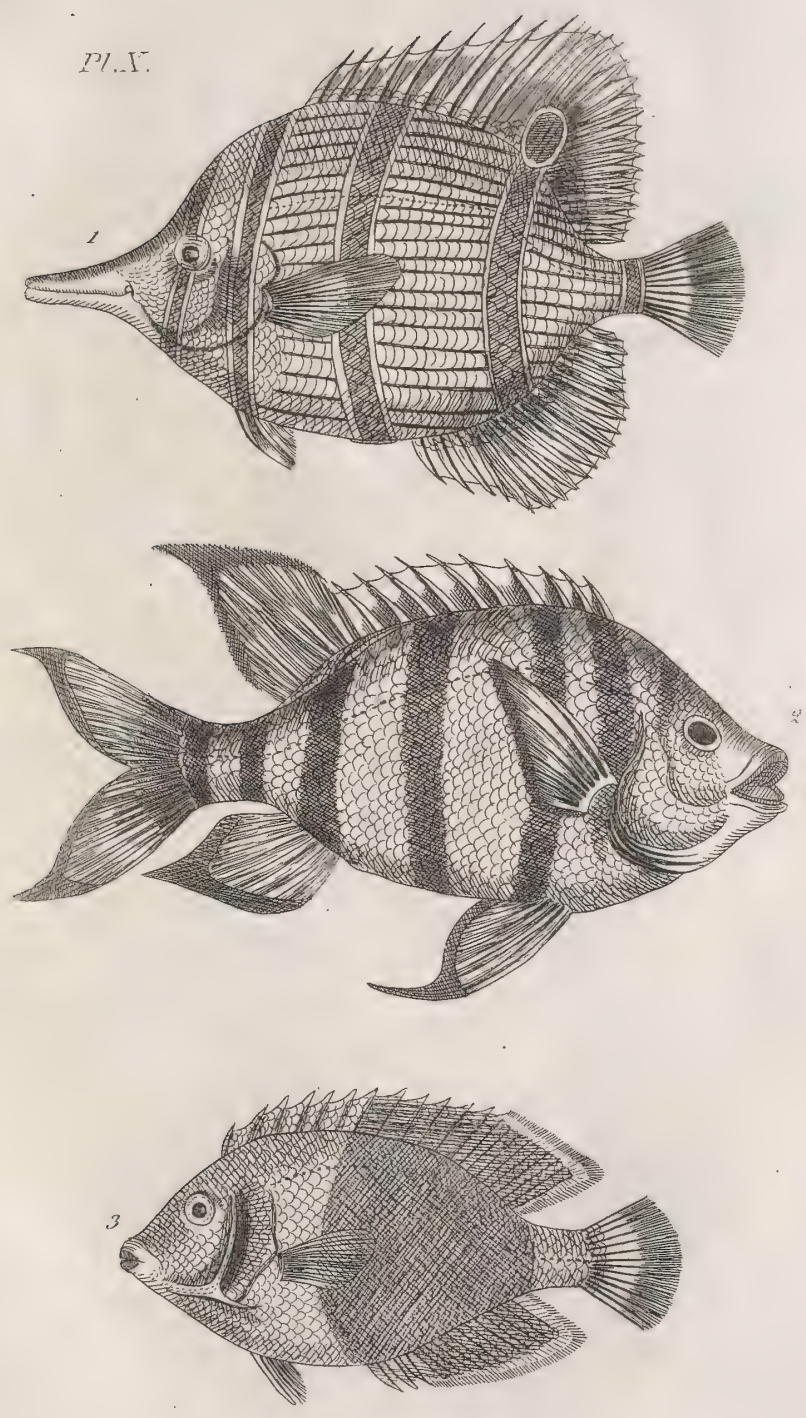

PI. II.

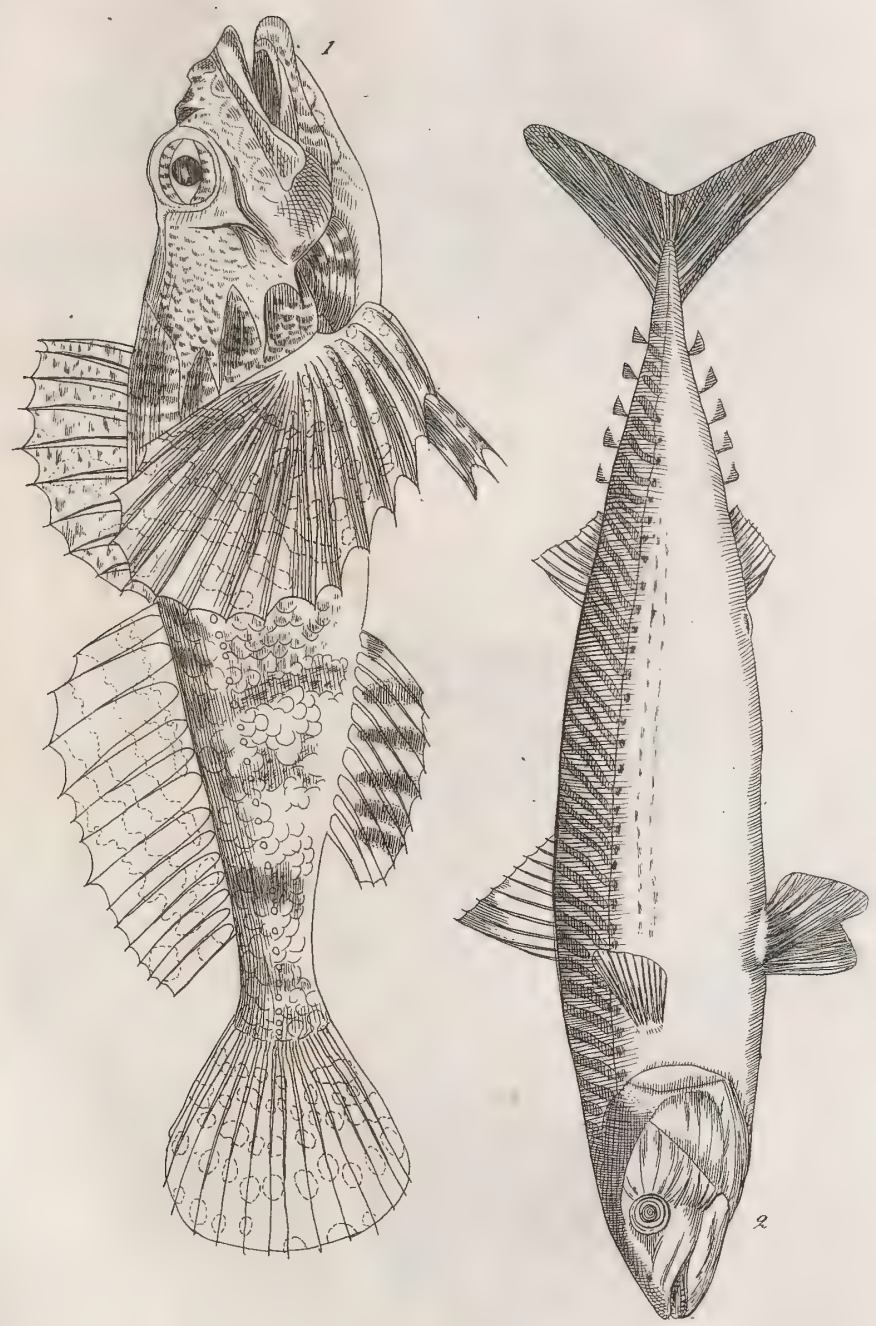



P.XII.
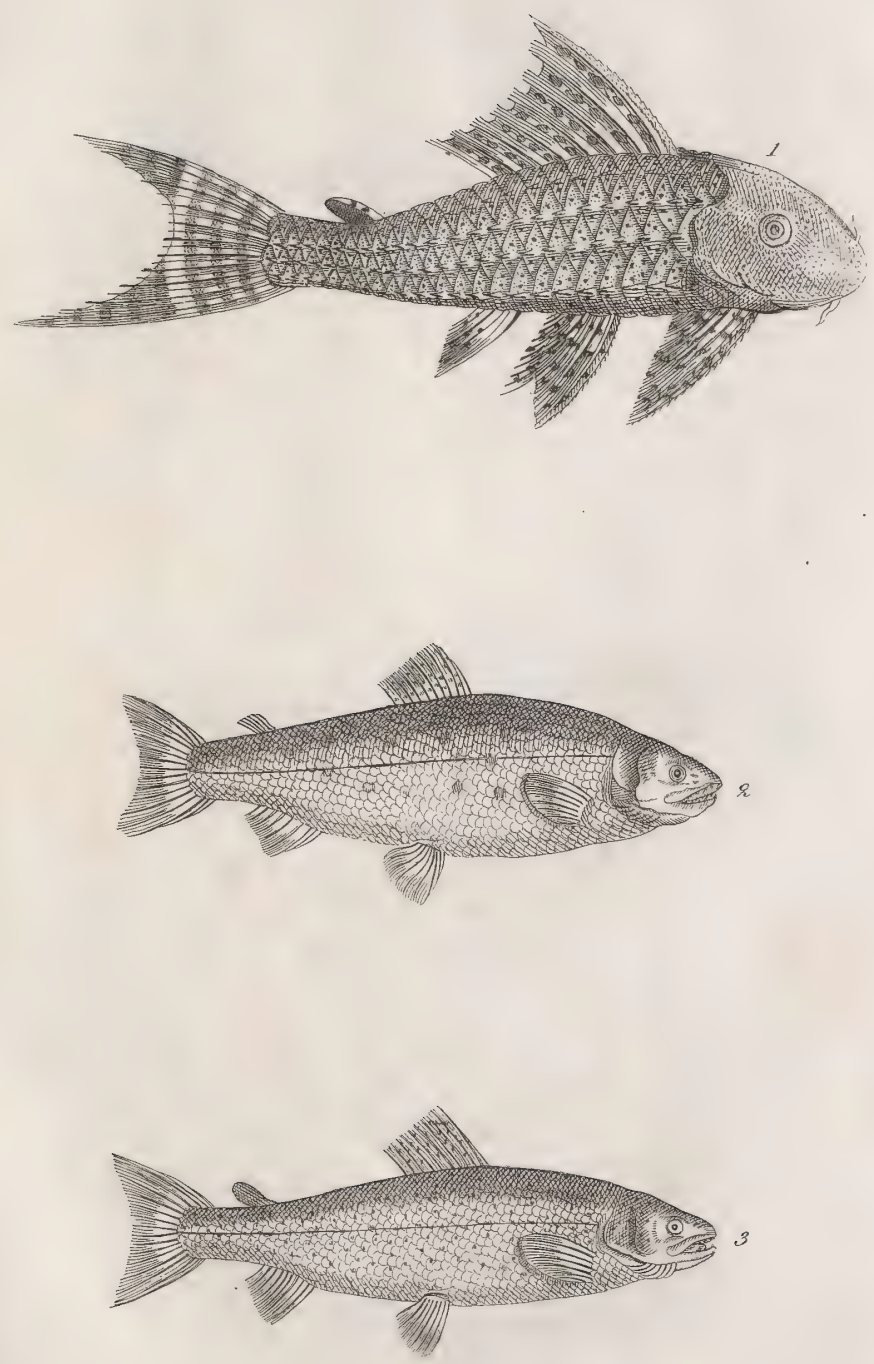

PL.XIII.
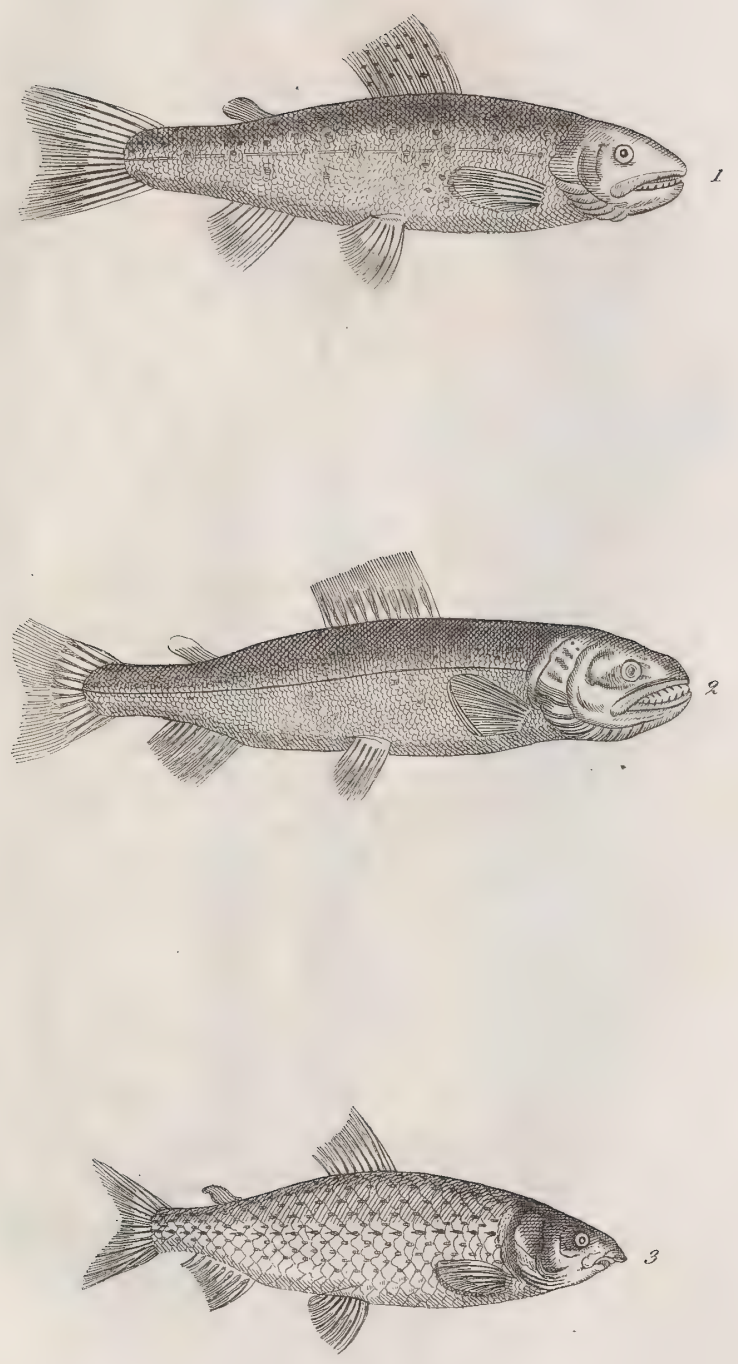


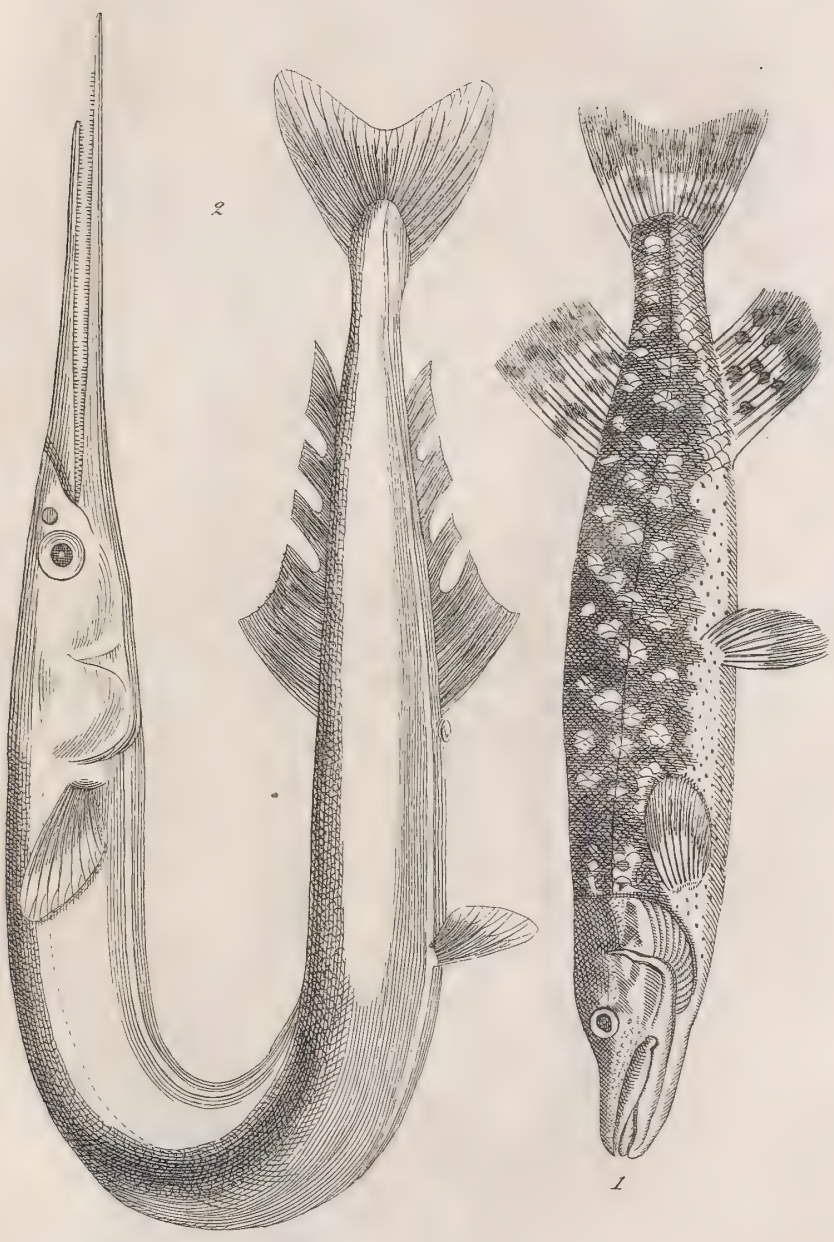



Pl.XV

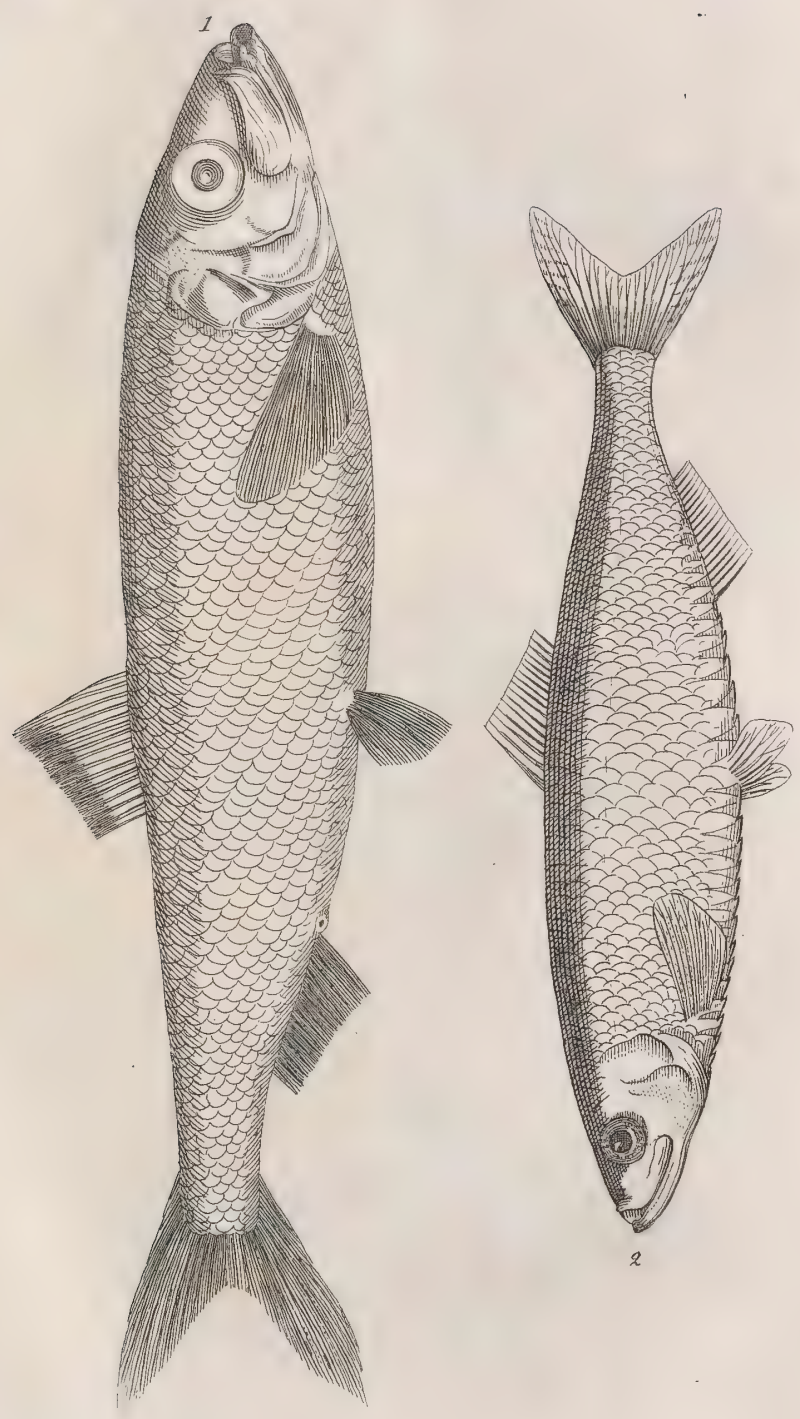





\section{II.XII.}
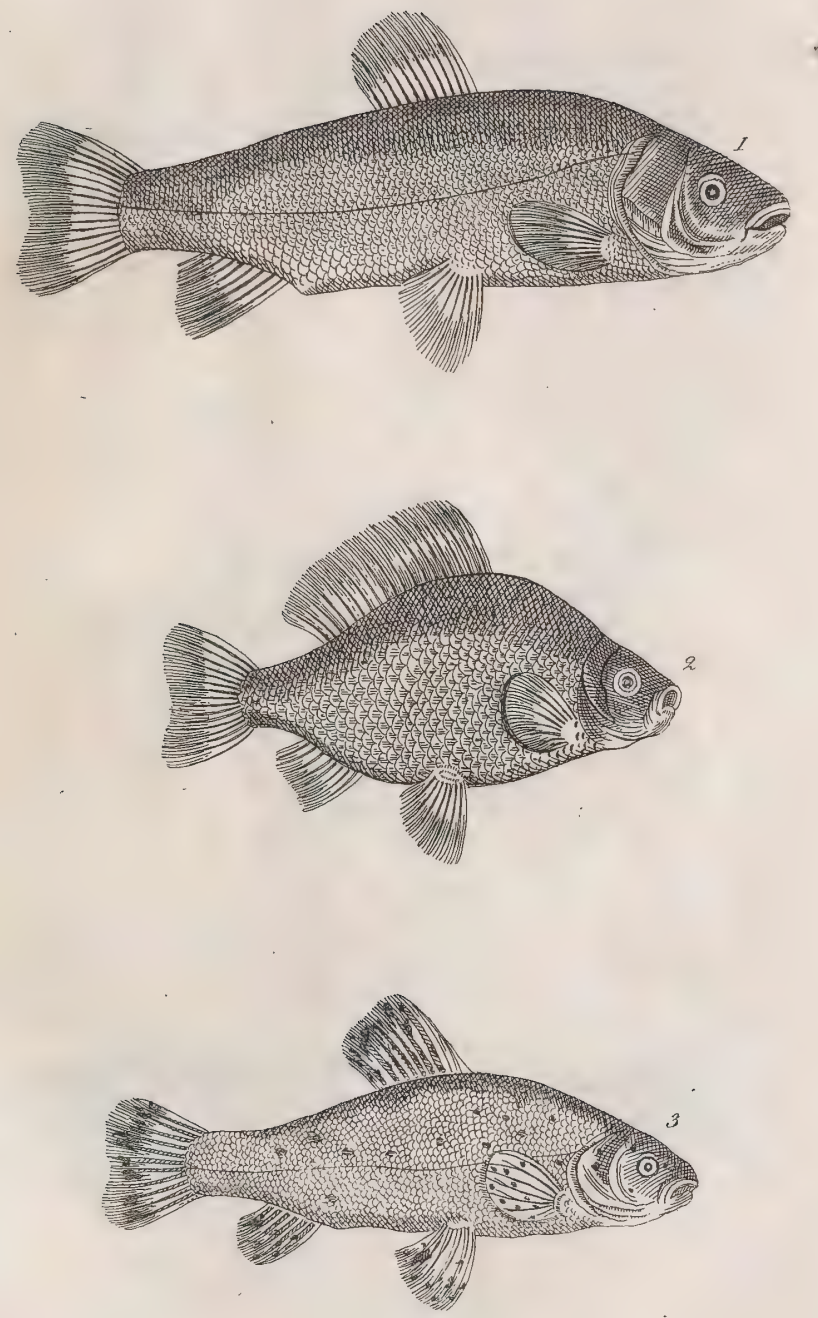

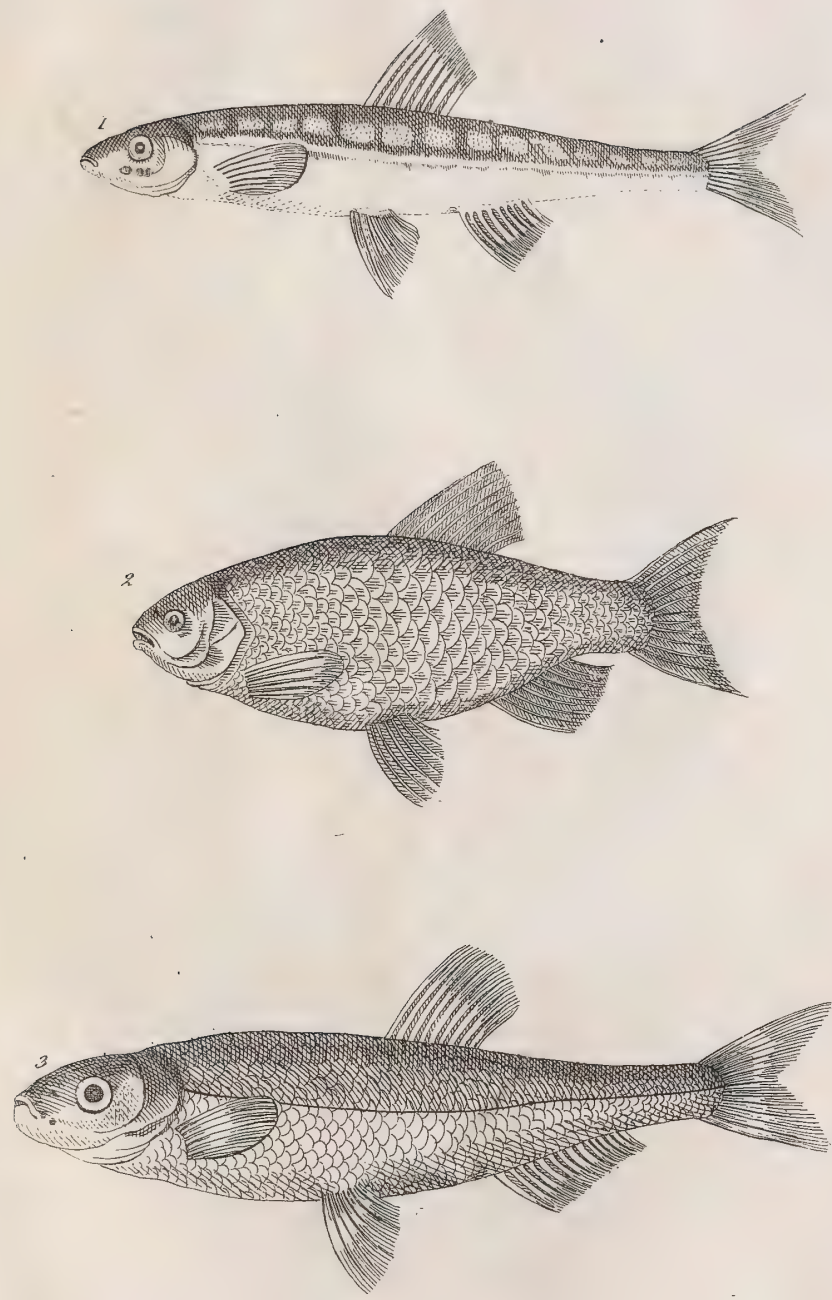



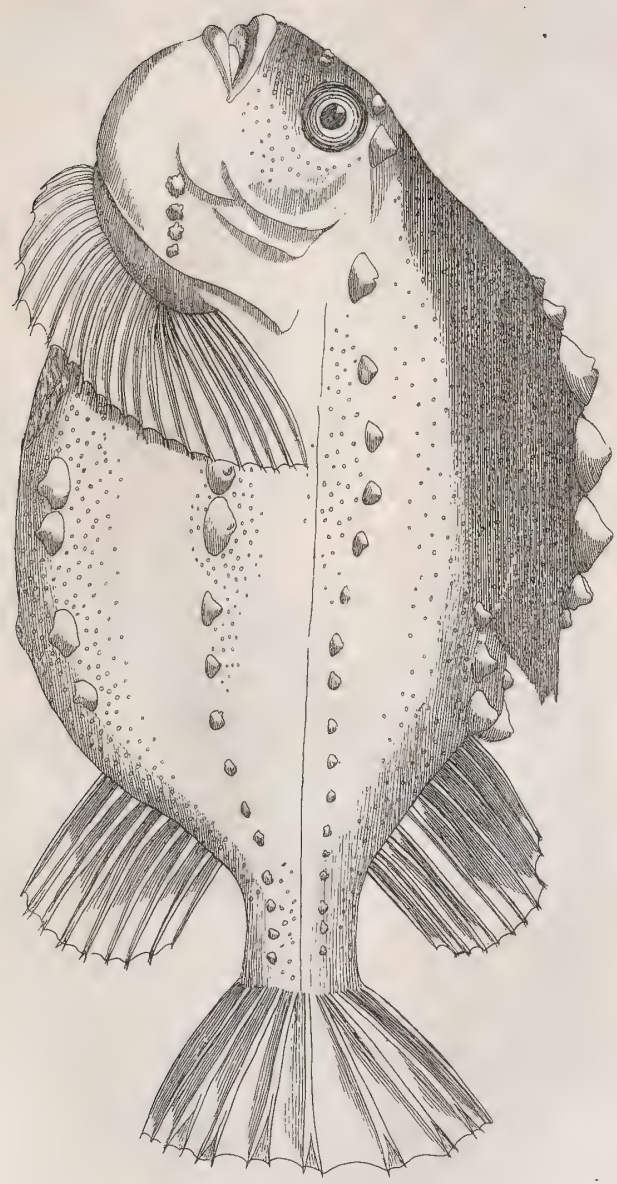



PLXIX

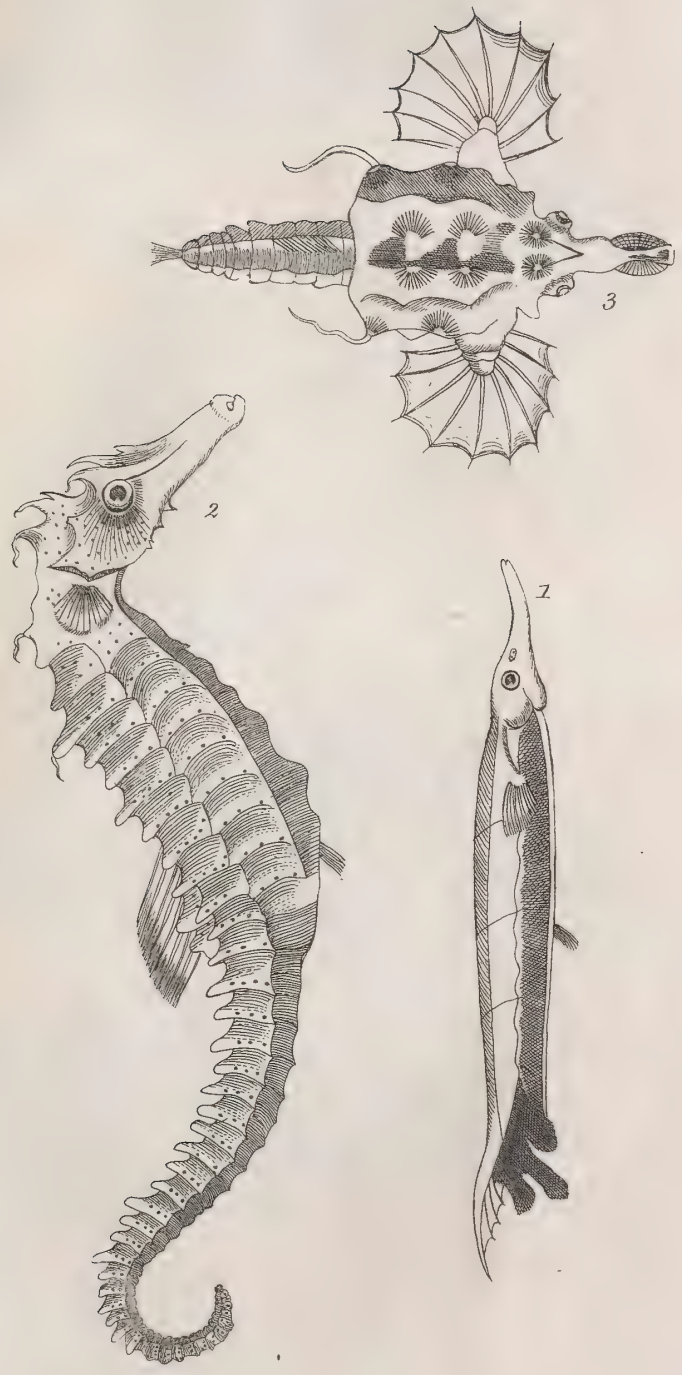



PEXX.

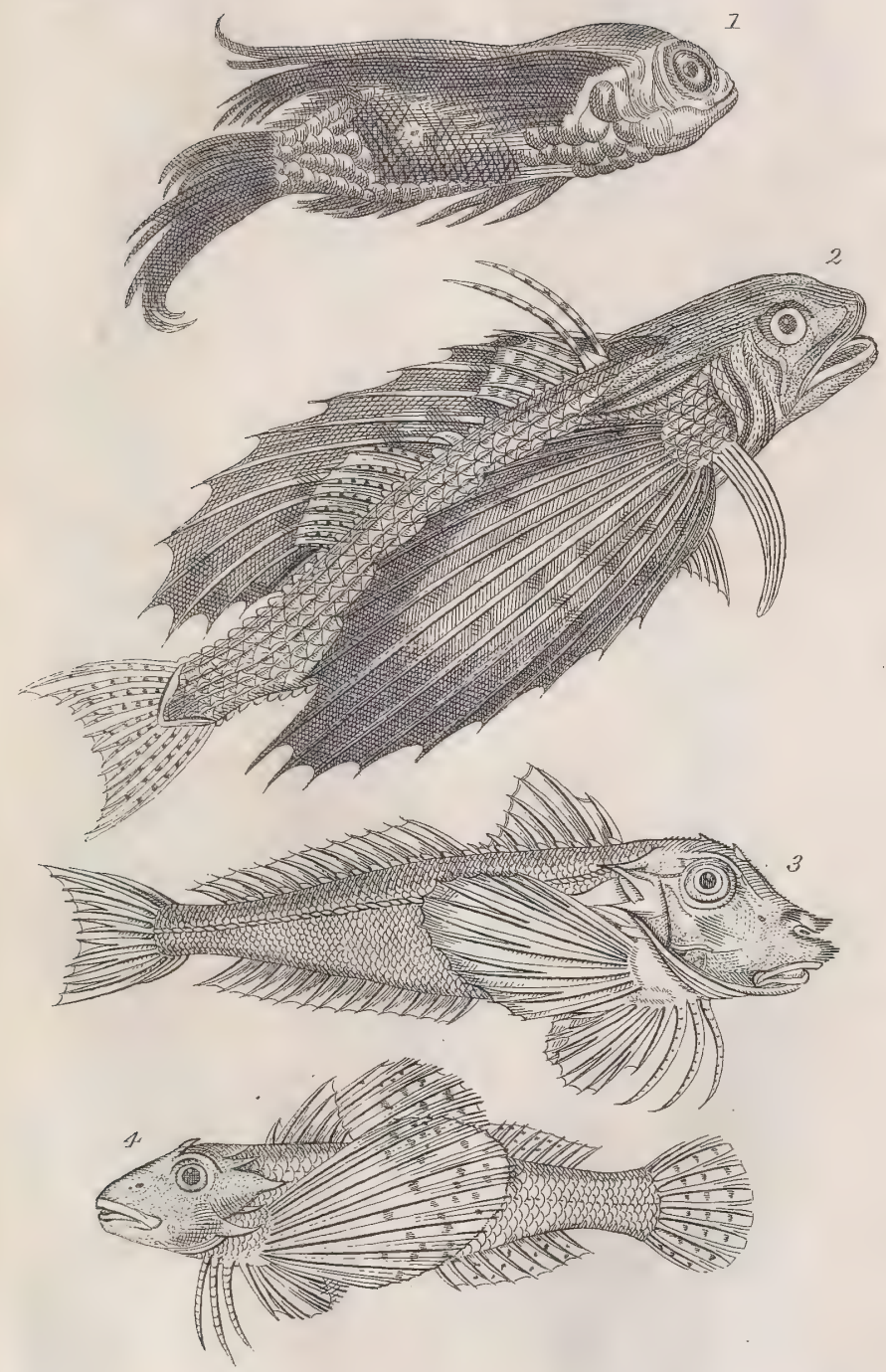



P7XXI.
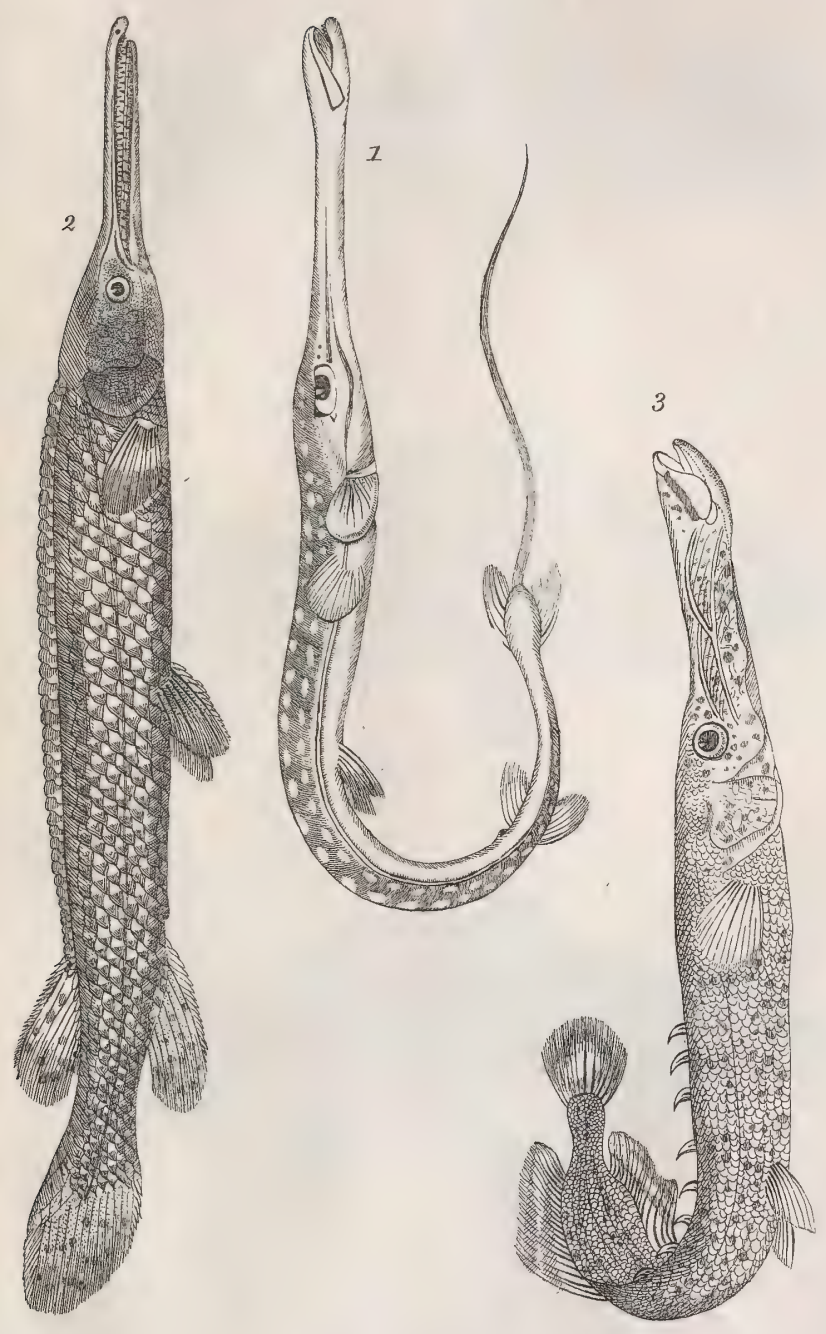

PIXXII.
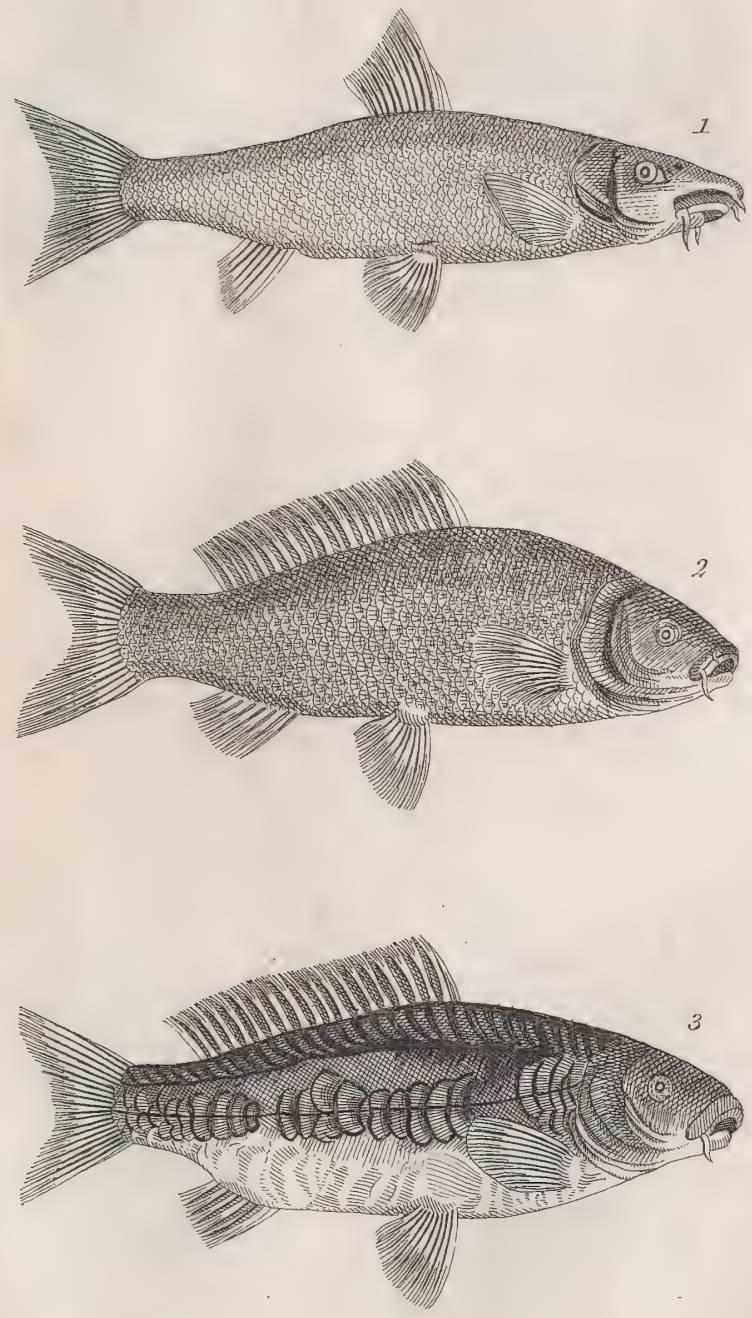



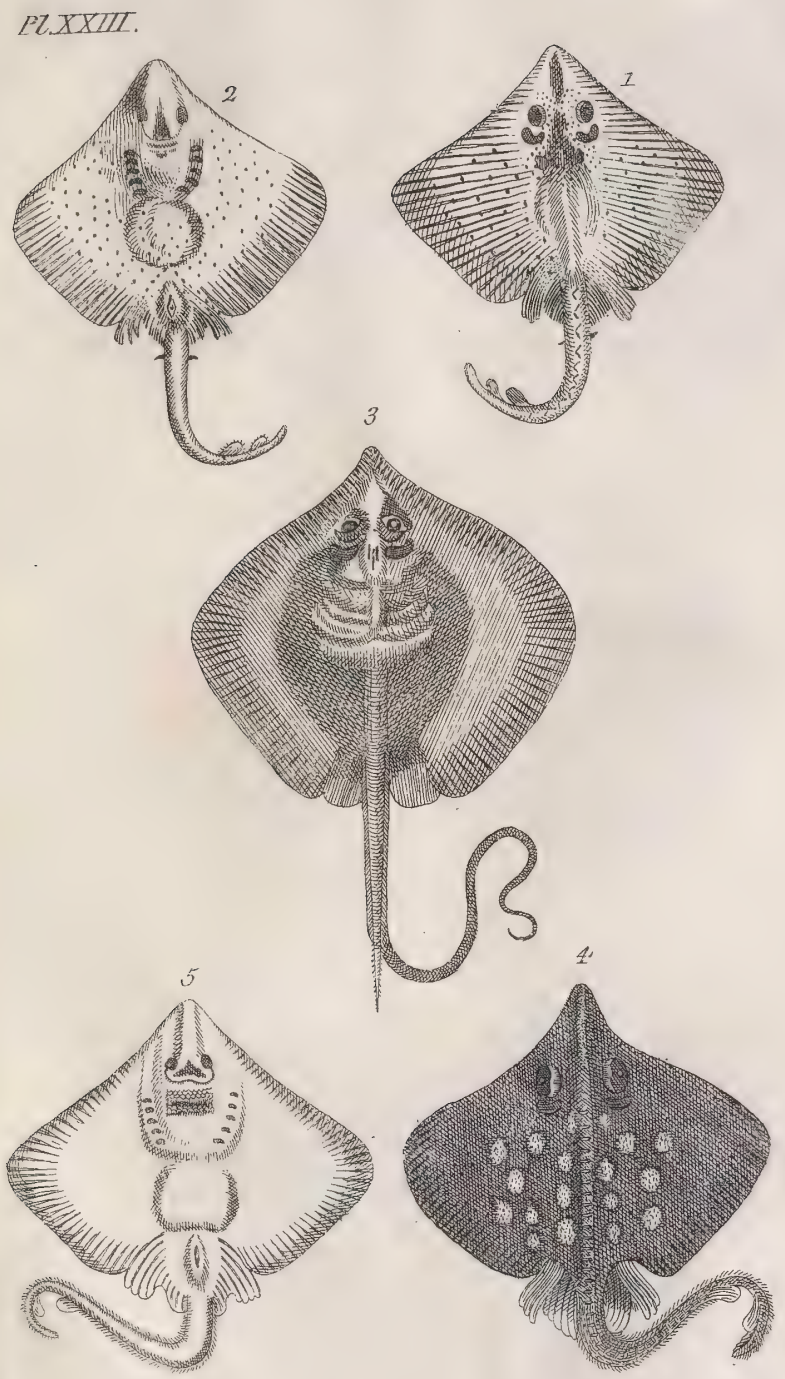




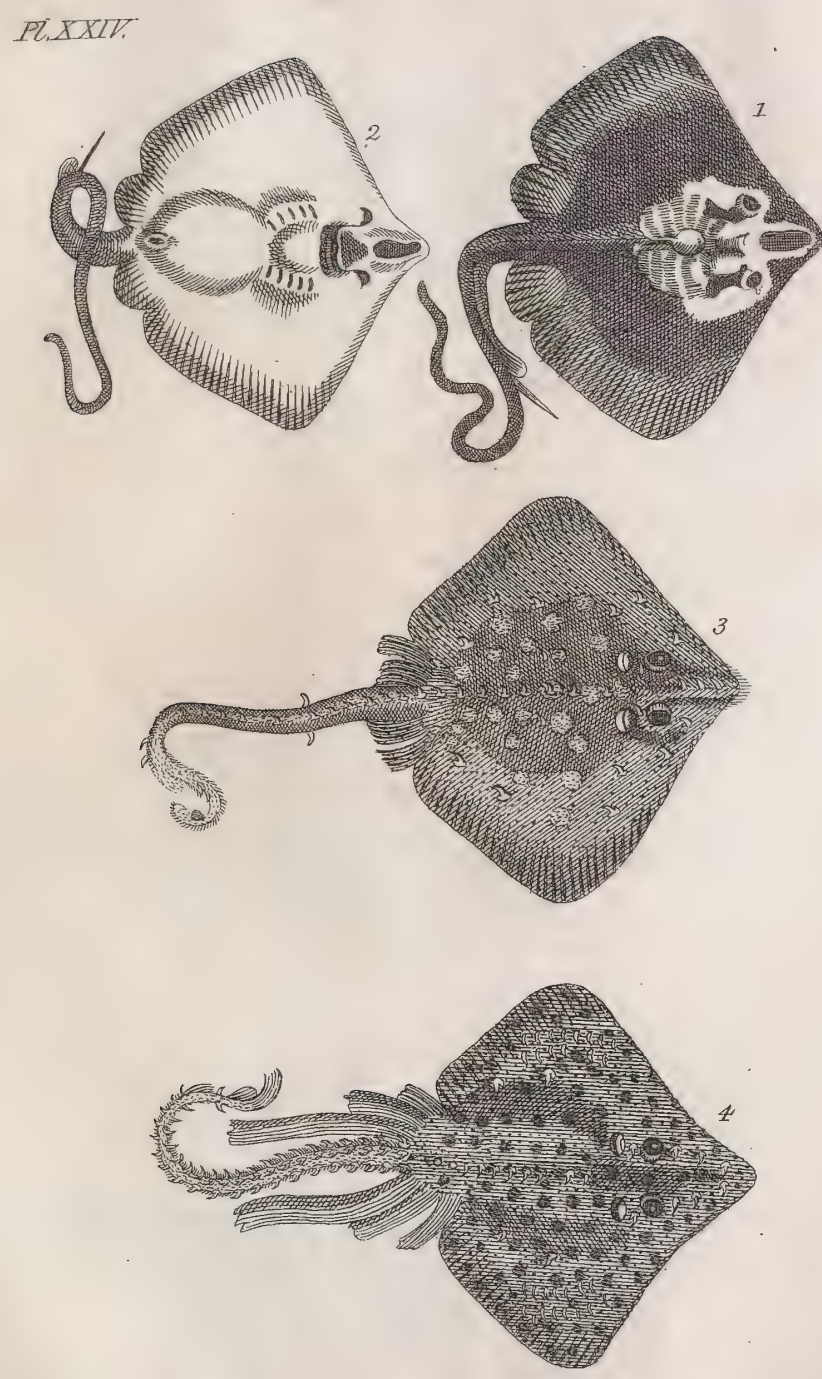



U. XXY.
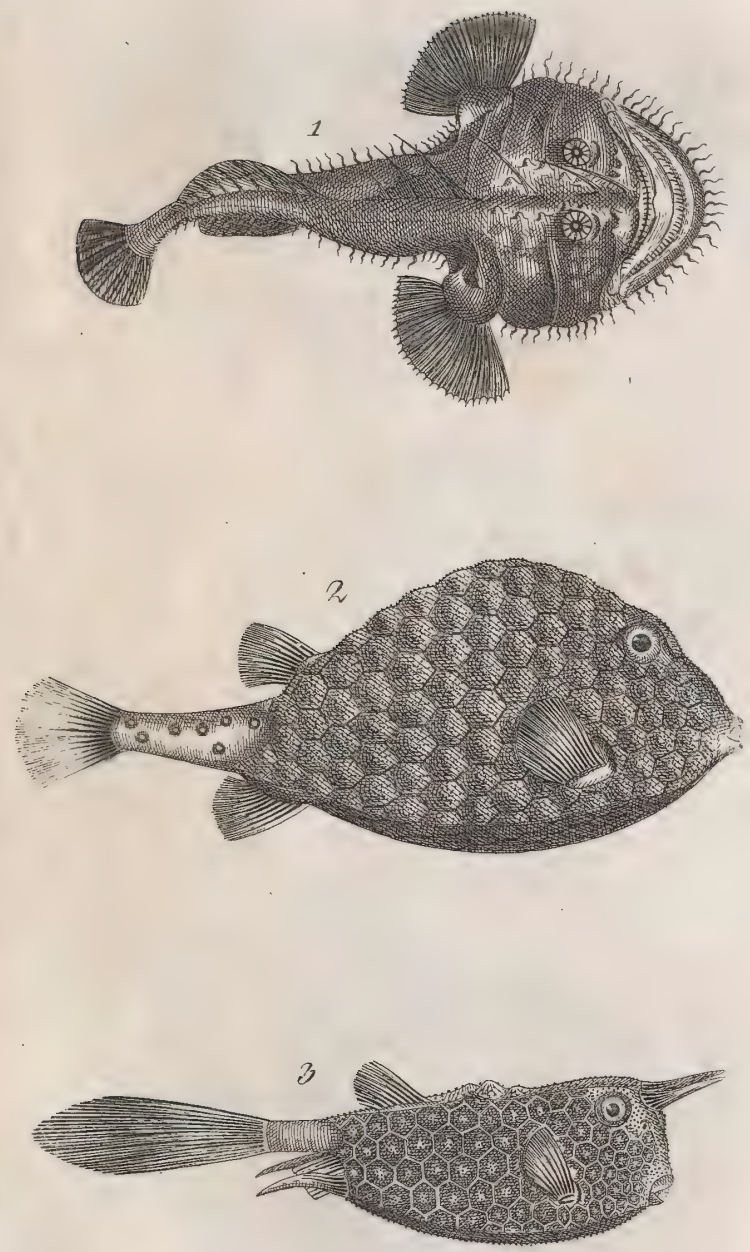

PL. TXVI.

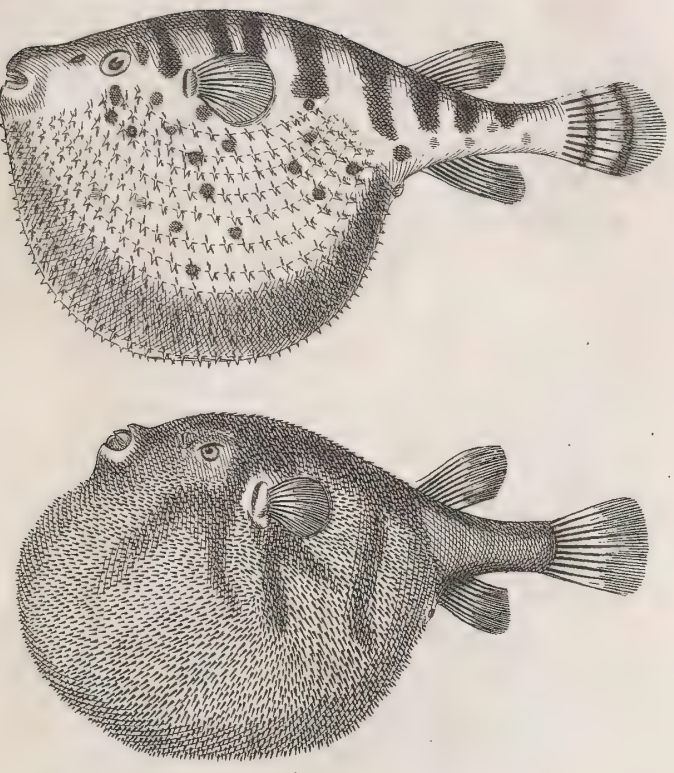

3

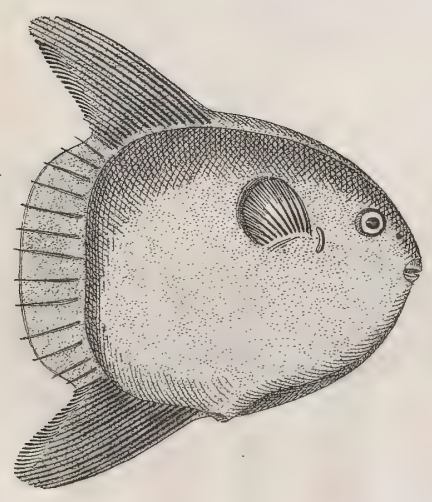




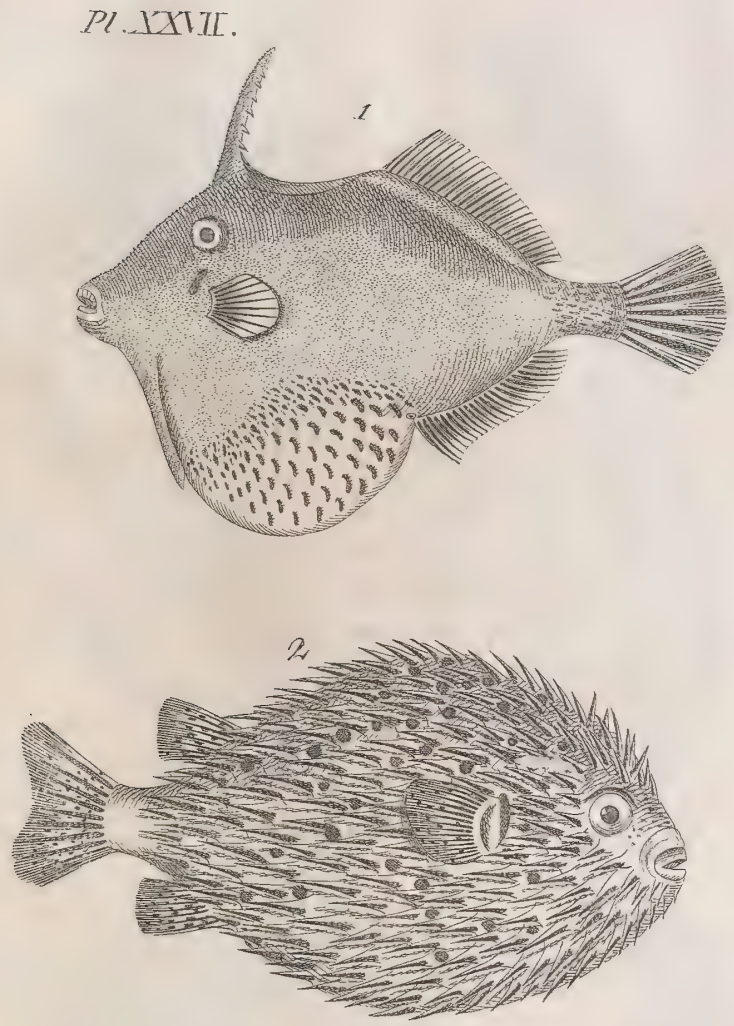

3

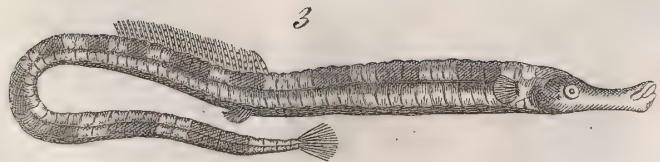




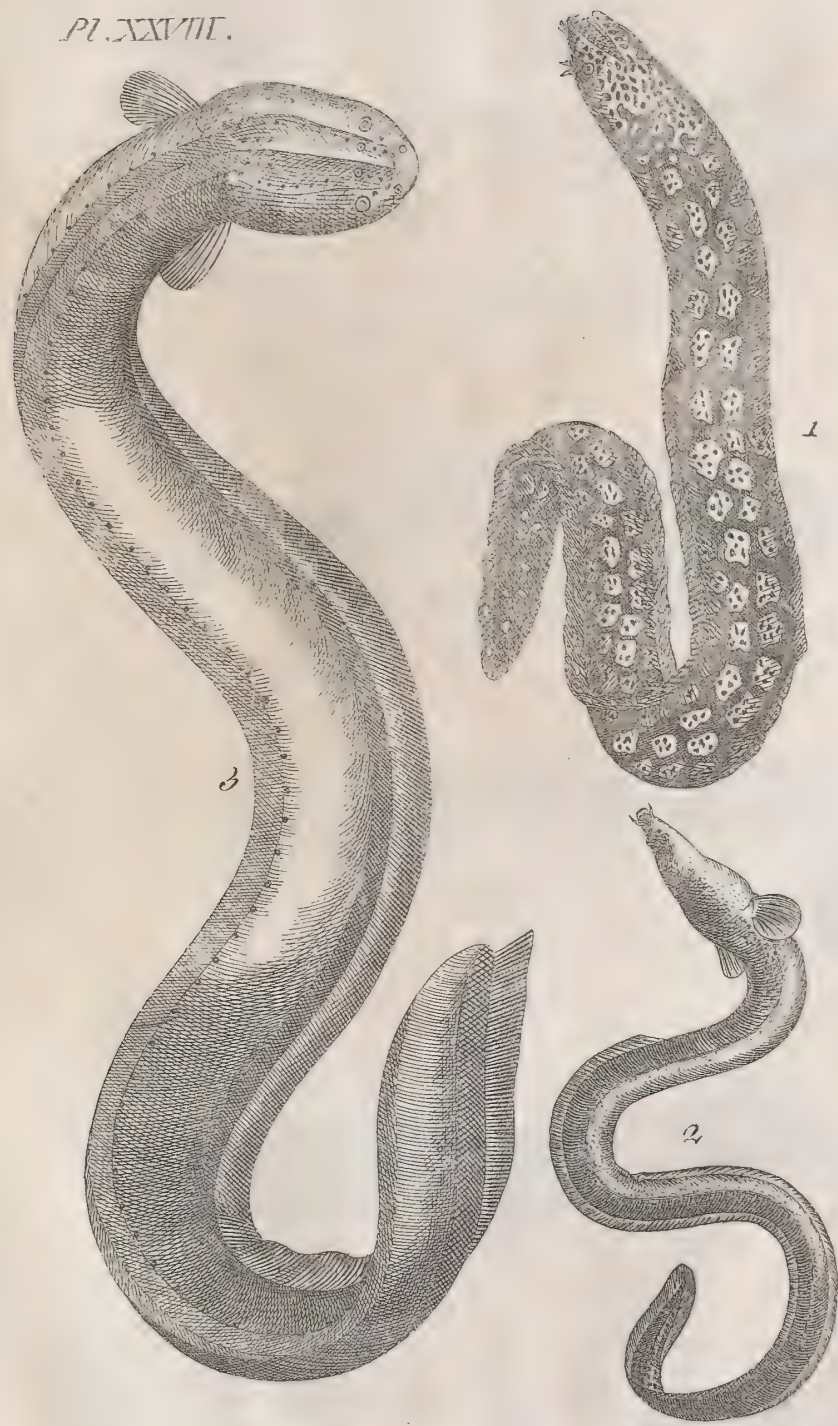


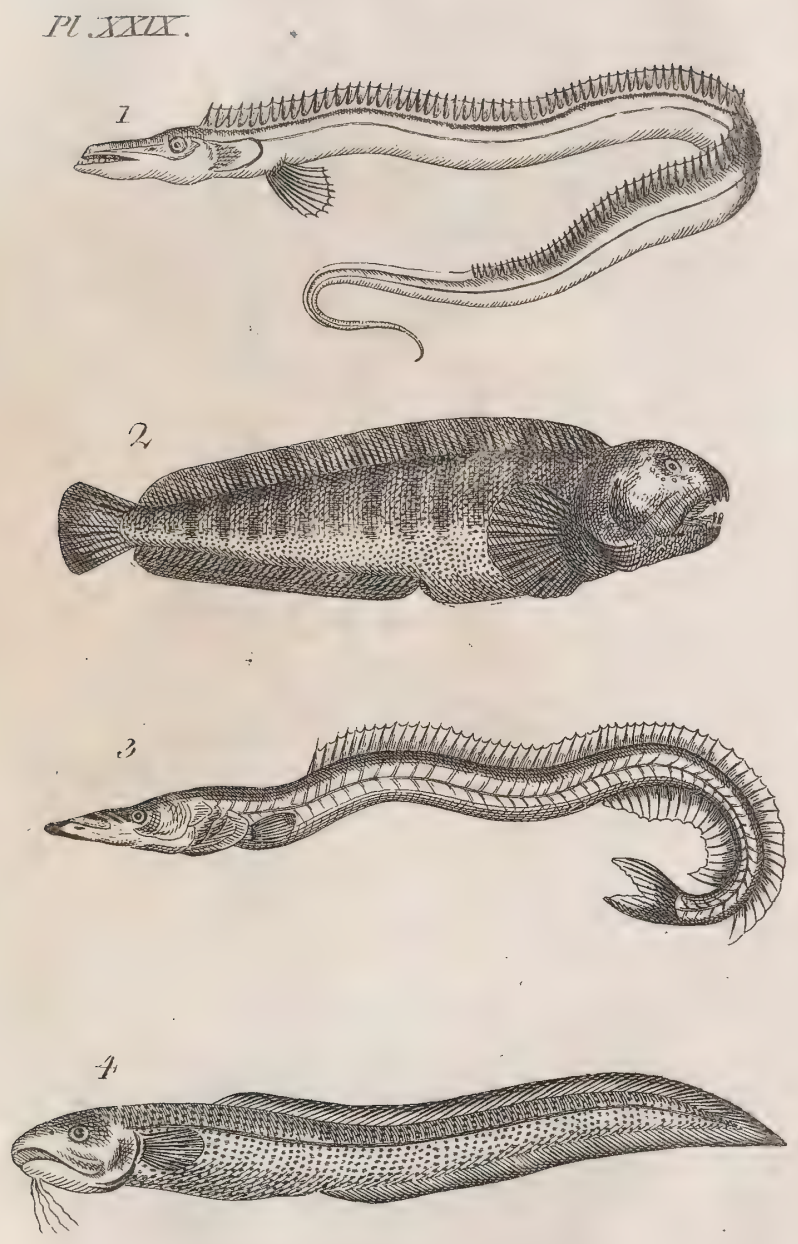



\section{PI.XX.}
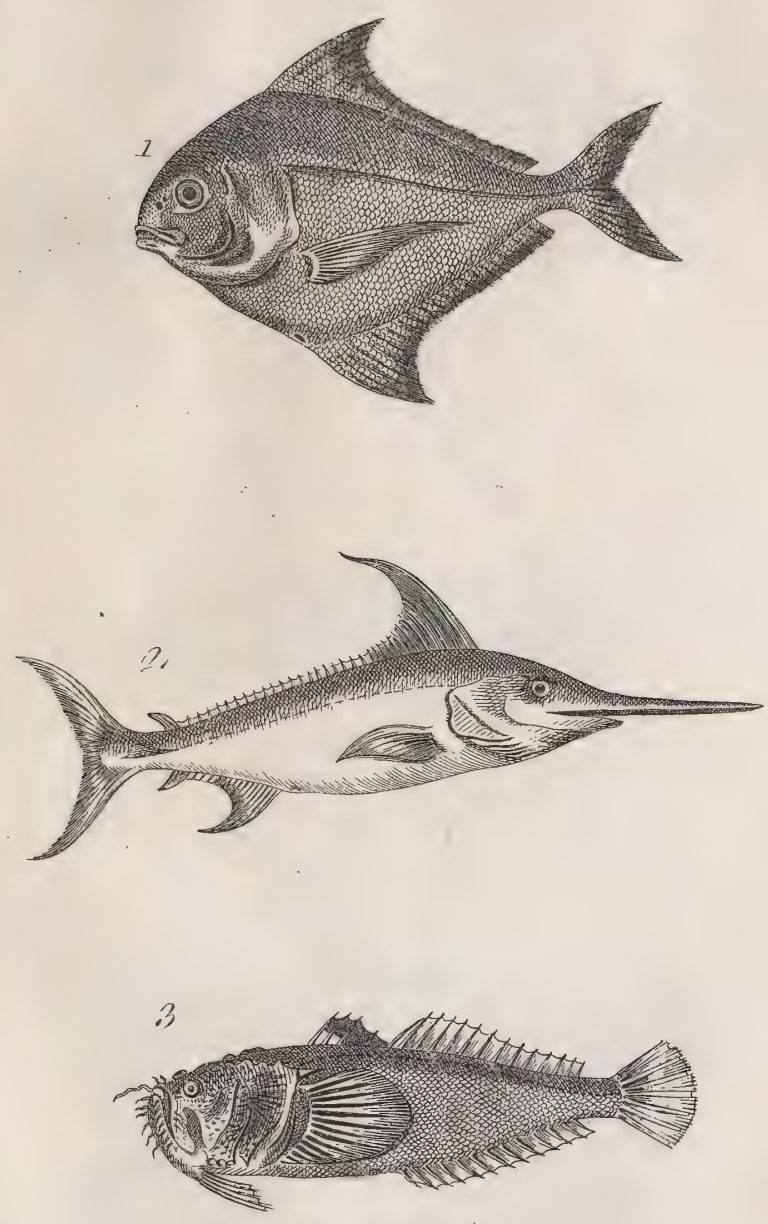

Pl:XXX7:.
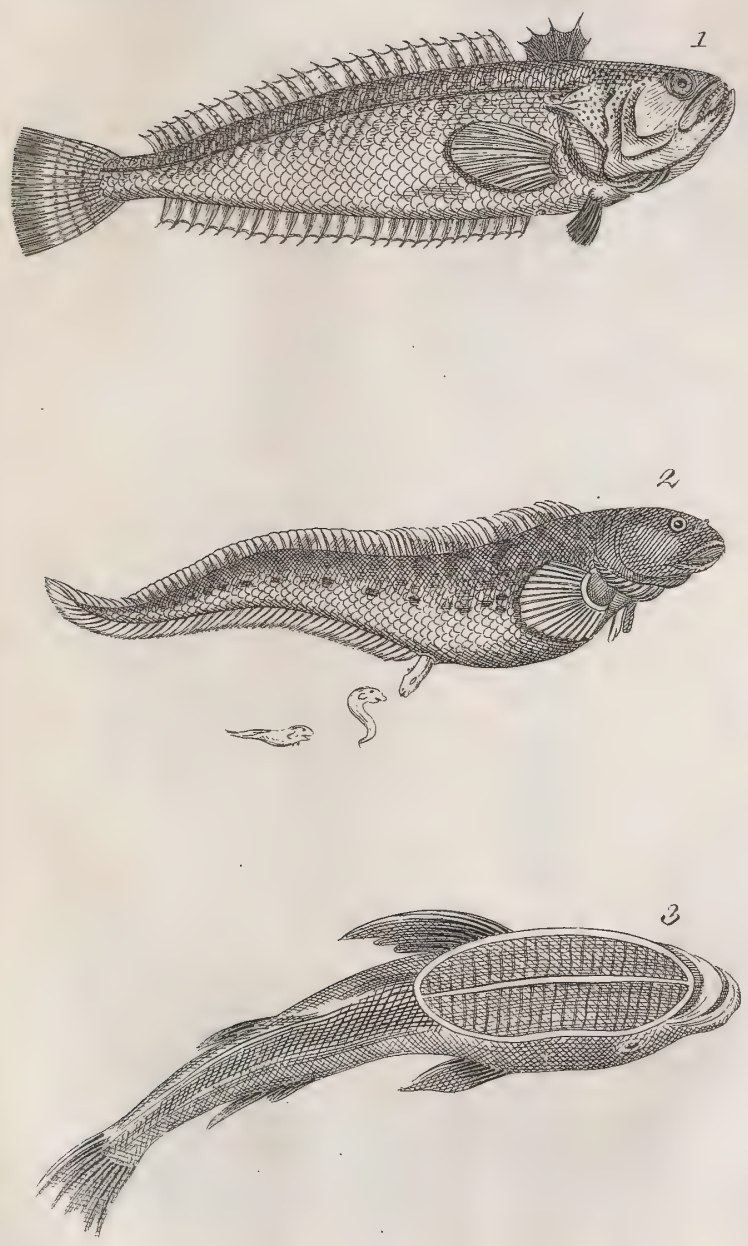


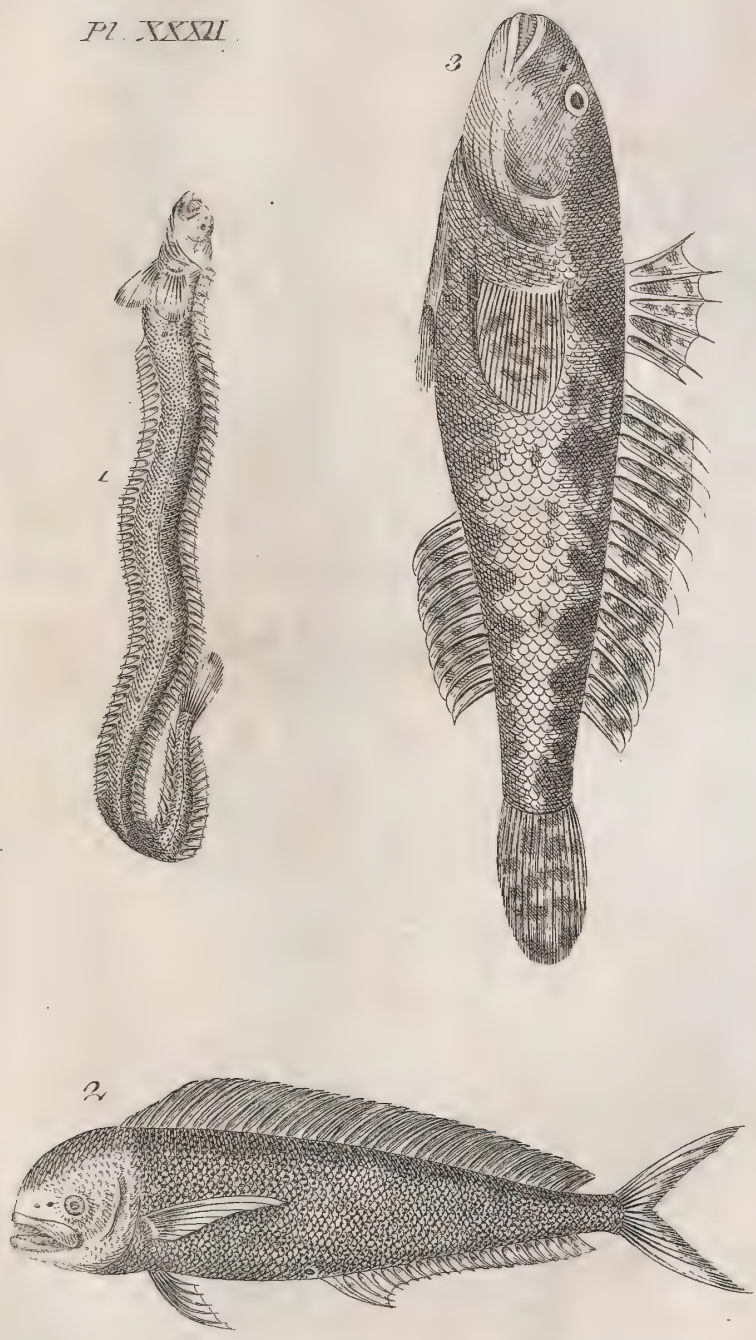

PLXXXIIL.

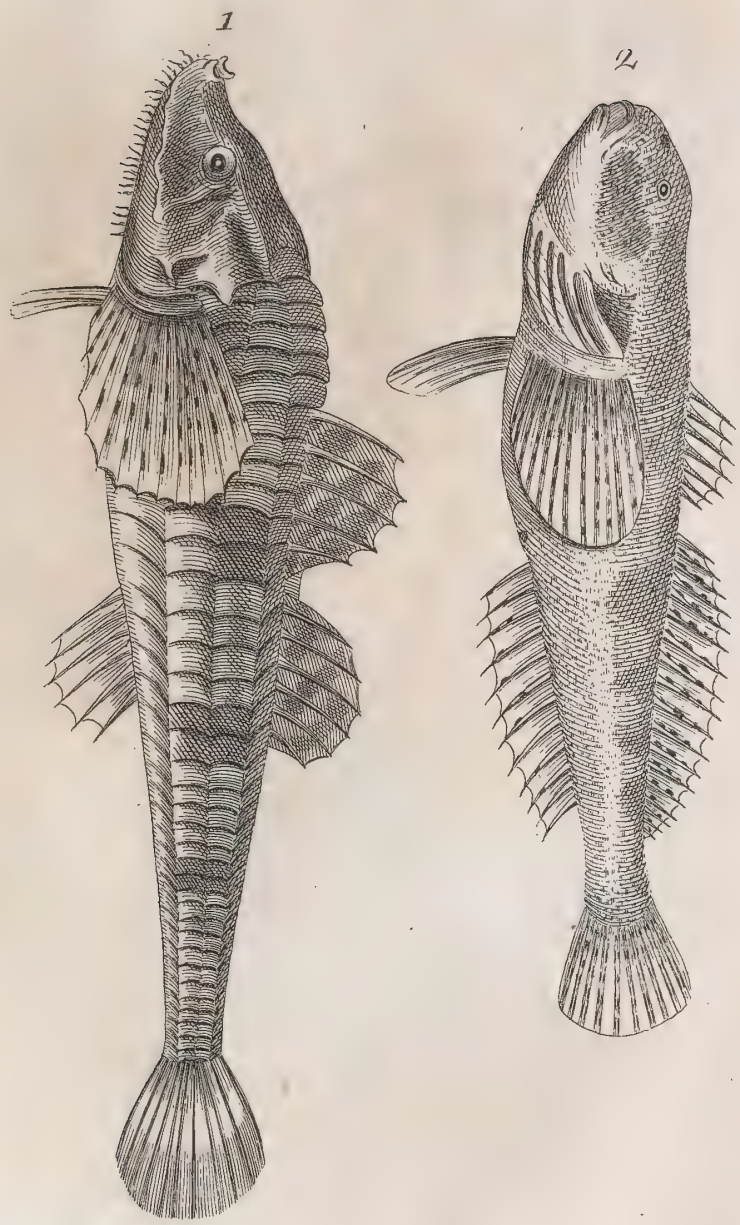




\section{.}




\section{P2. EXIZT}
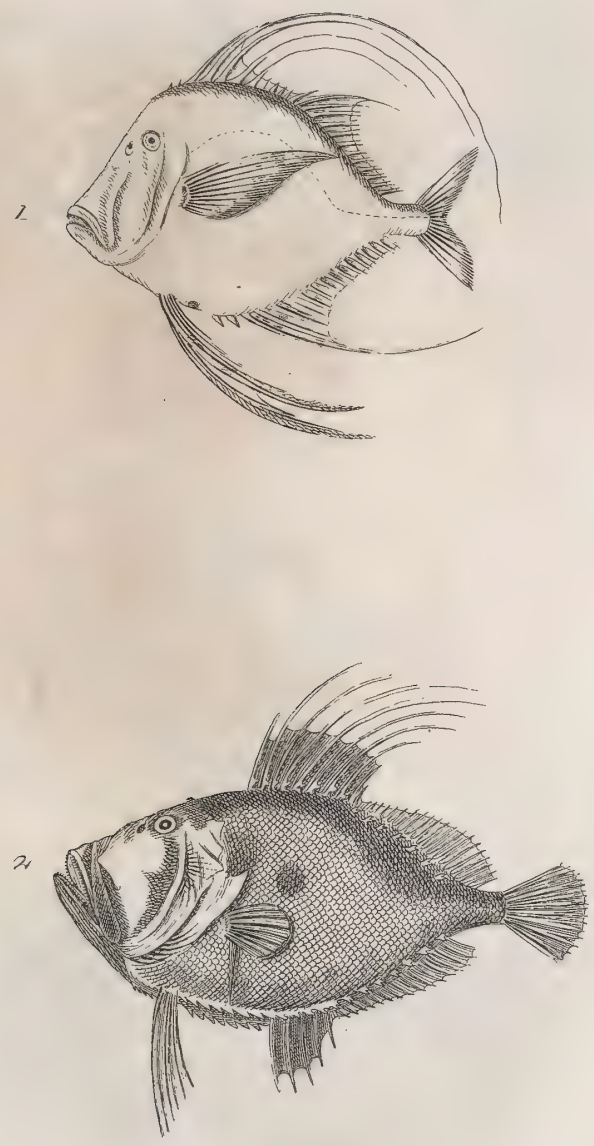

Pl. SXSV.
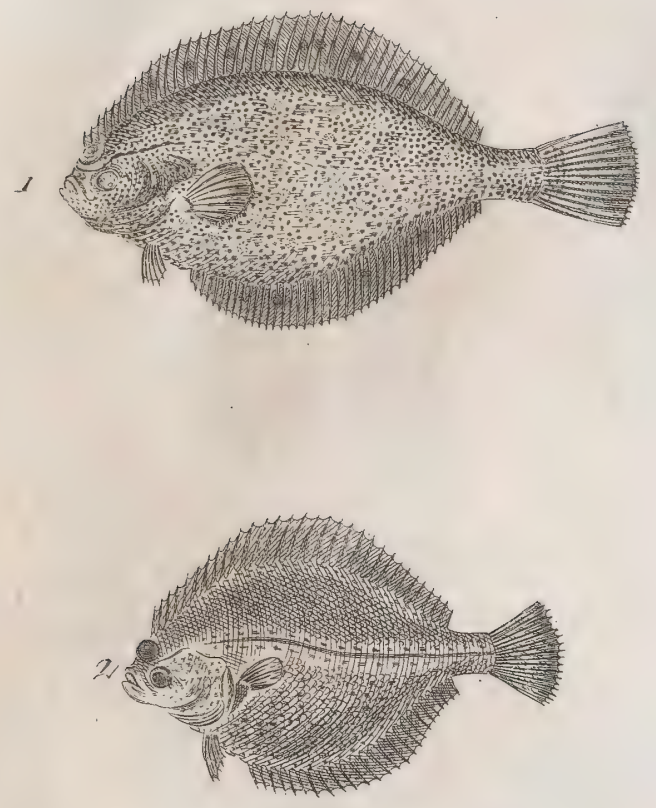

3

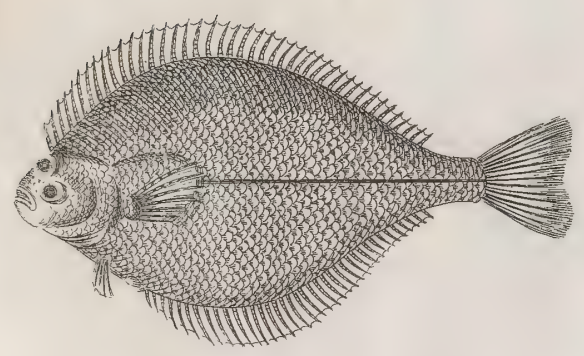





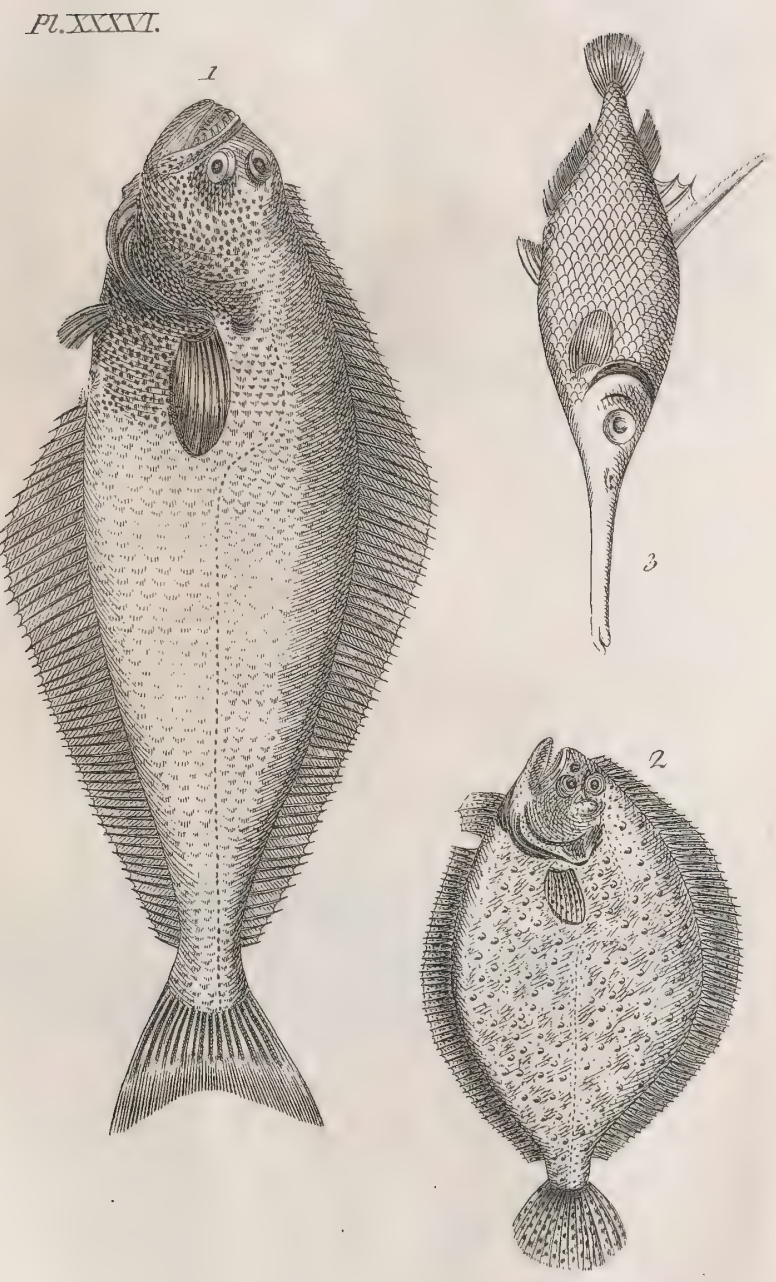



Pl. JPITI
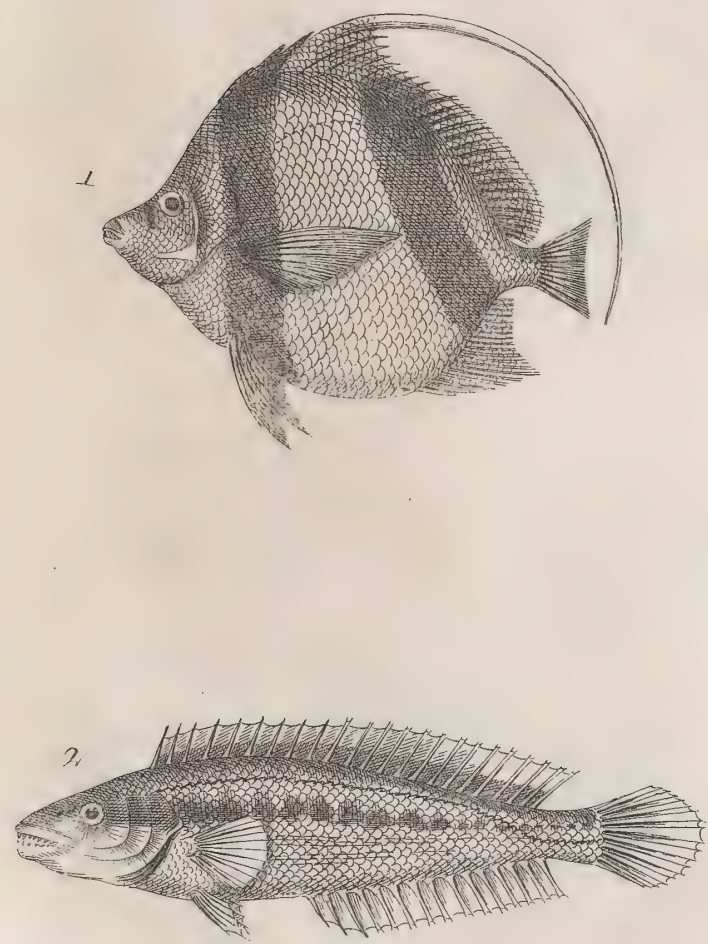

PL. XXXVII.
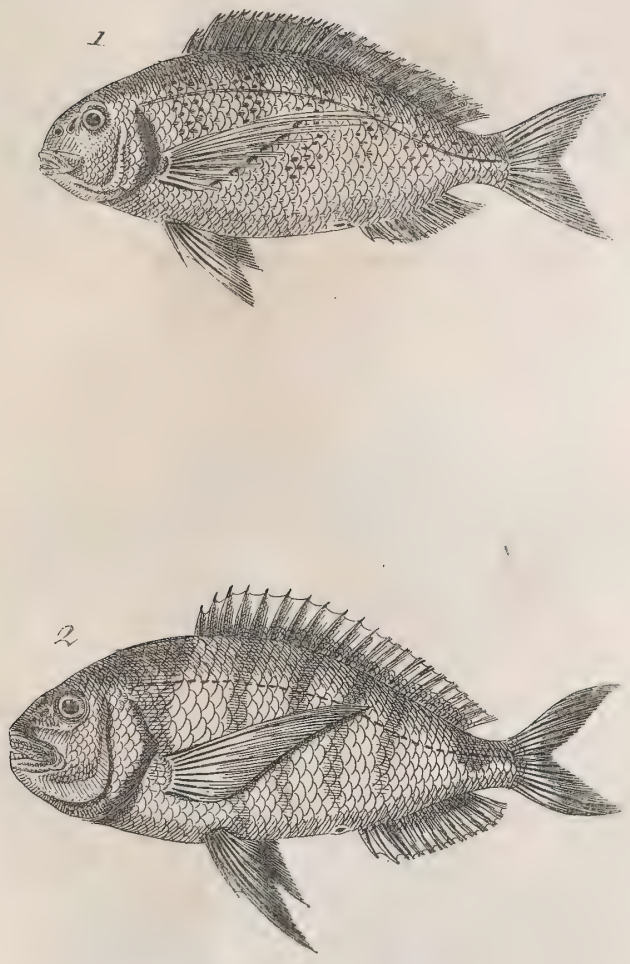

$P L . X X X I X$.
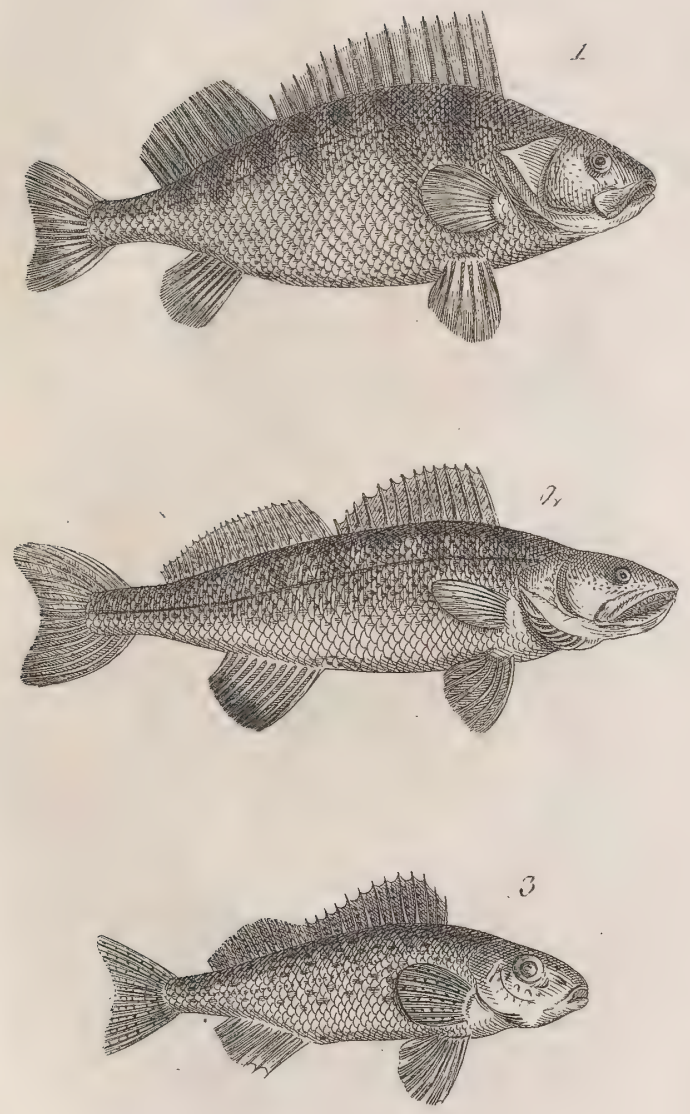


\section{Pl. XI.}

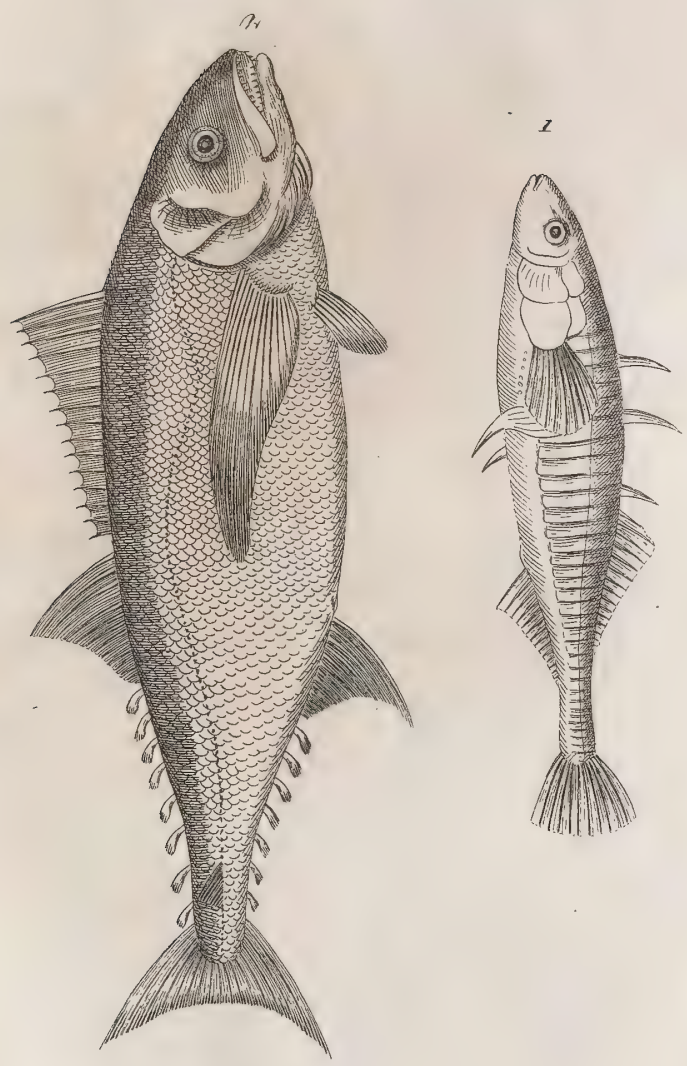



P.सWL.

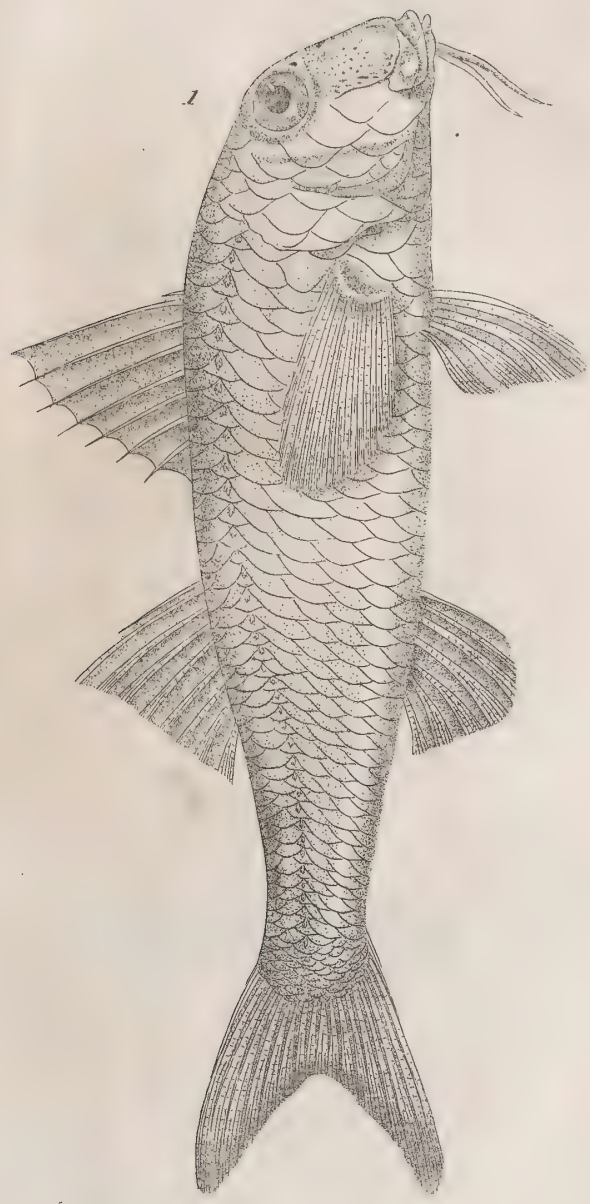





프. IIIII.

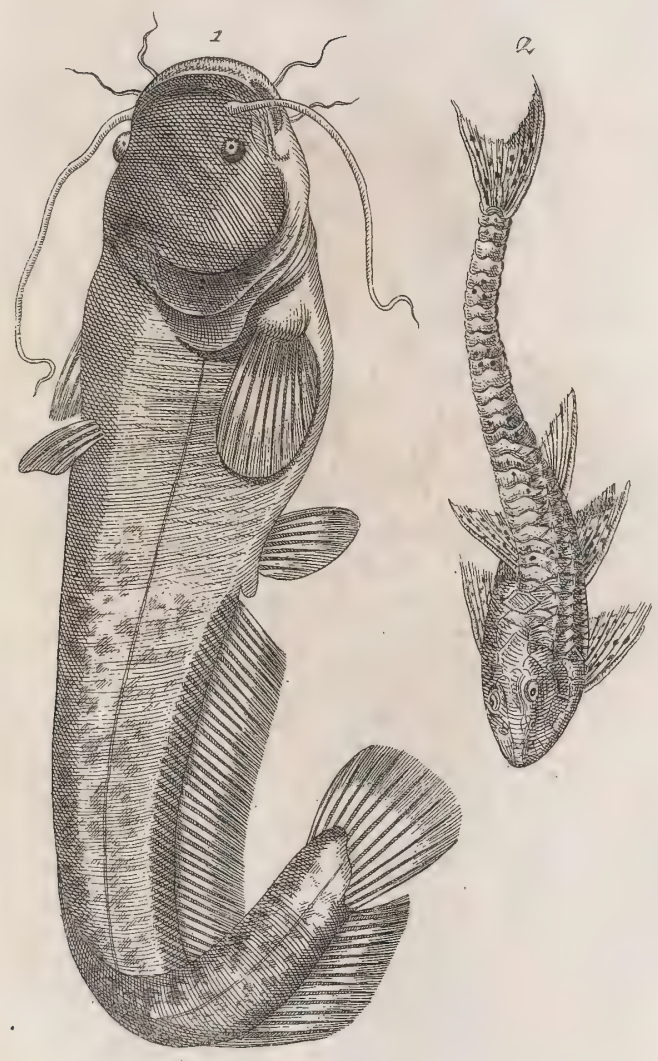





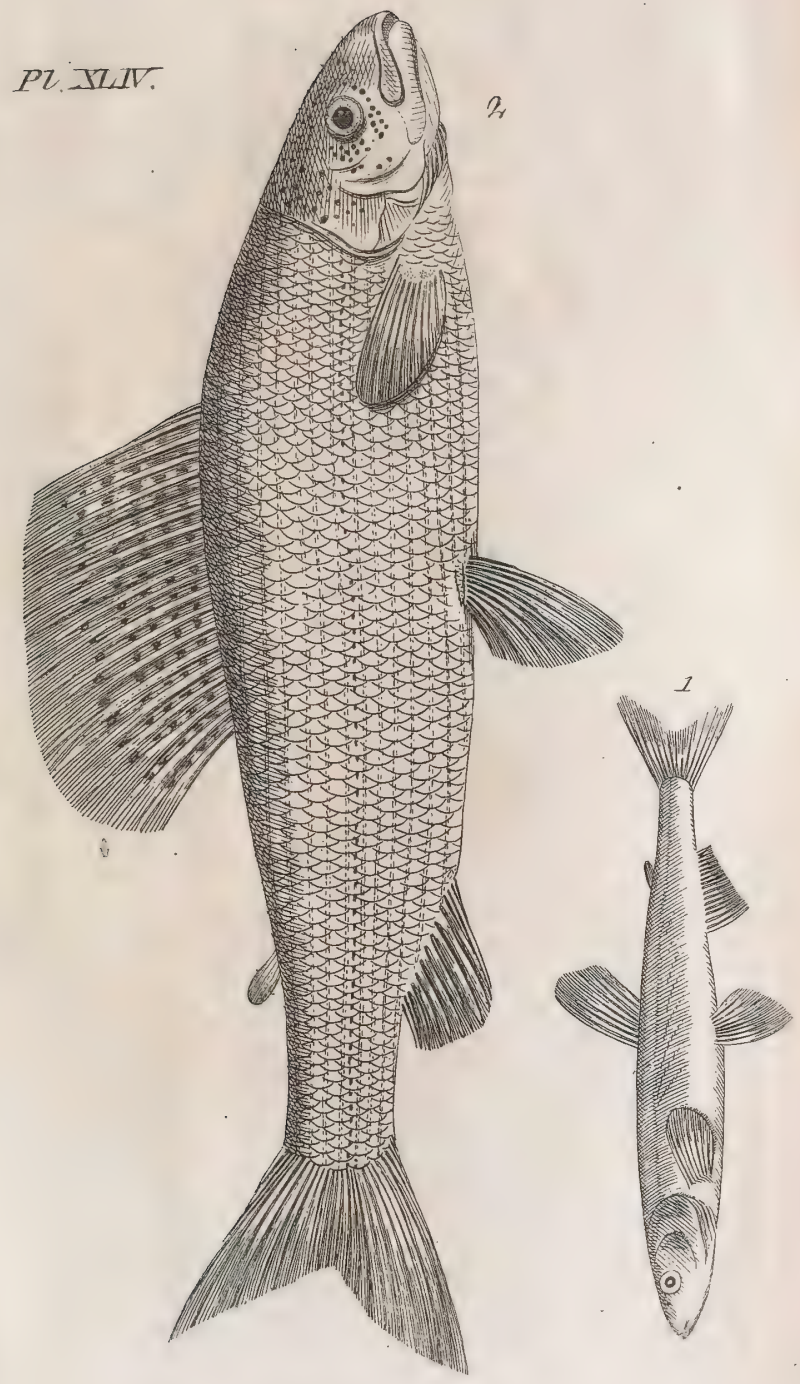




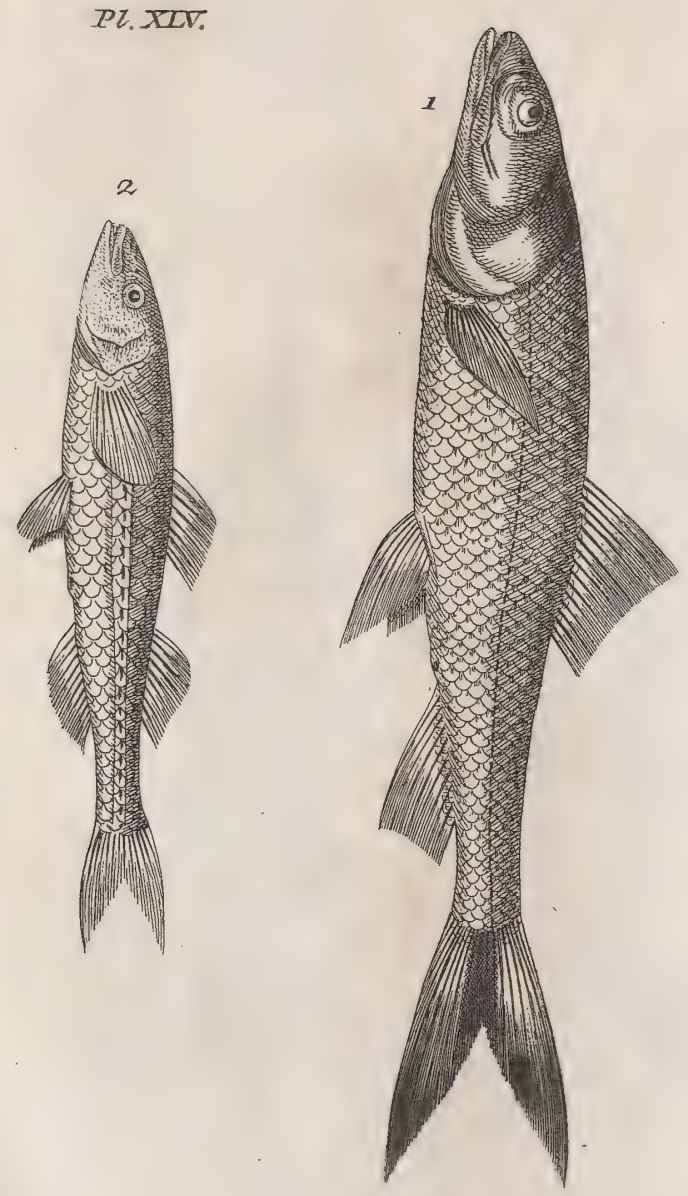

PL.XLVI.

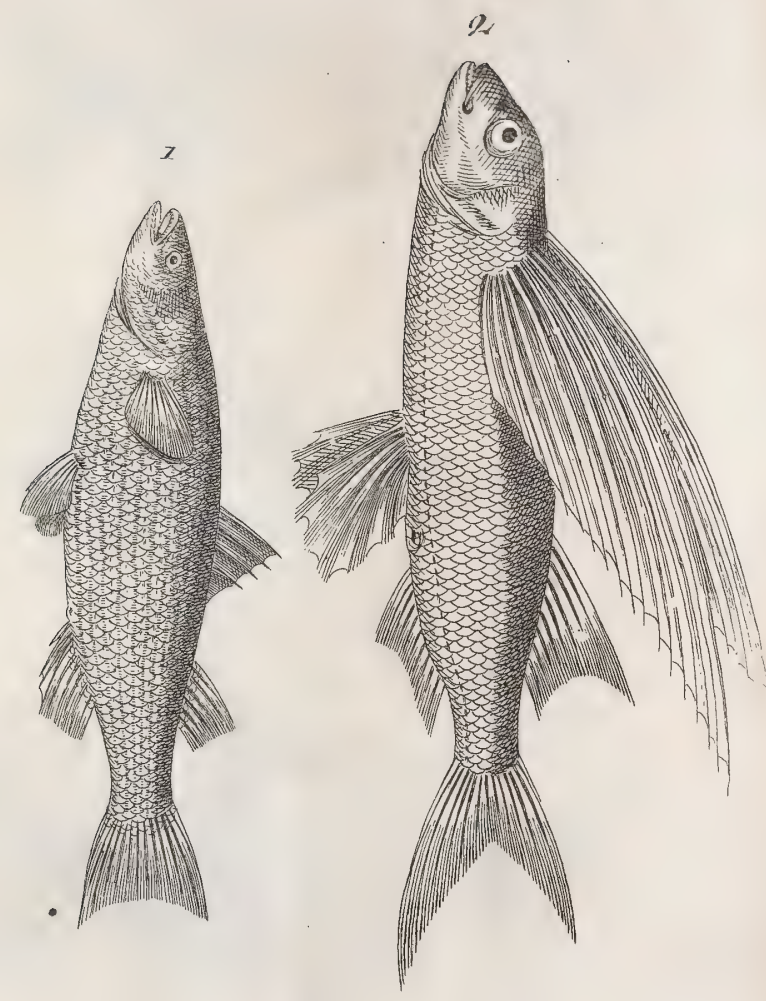


Pl:XIVII.

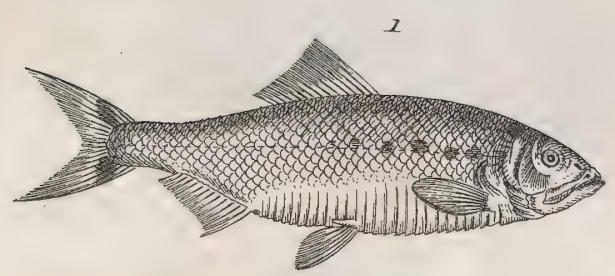

2
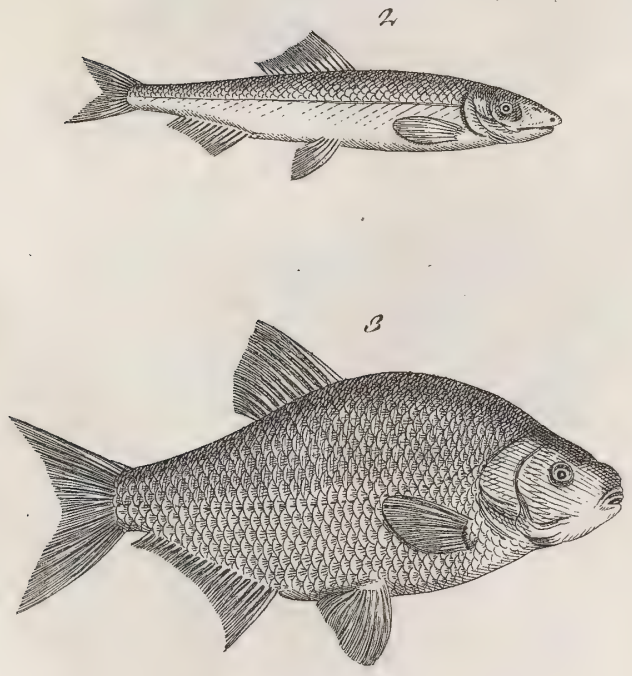



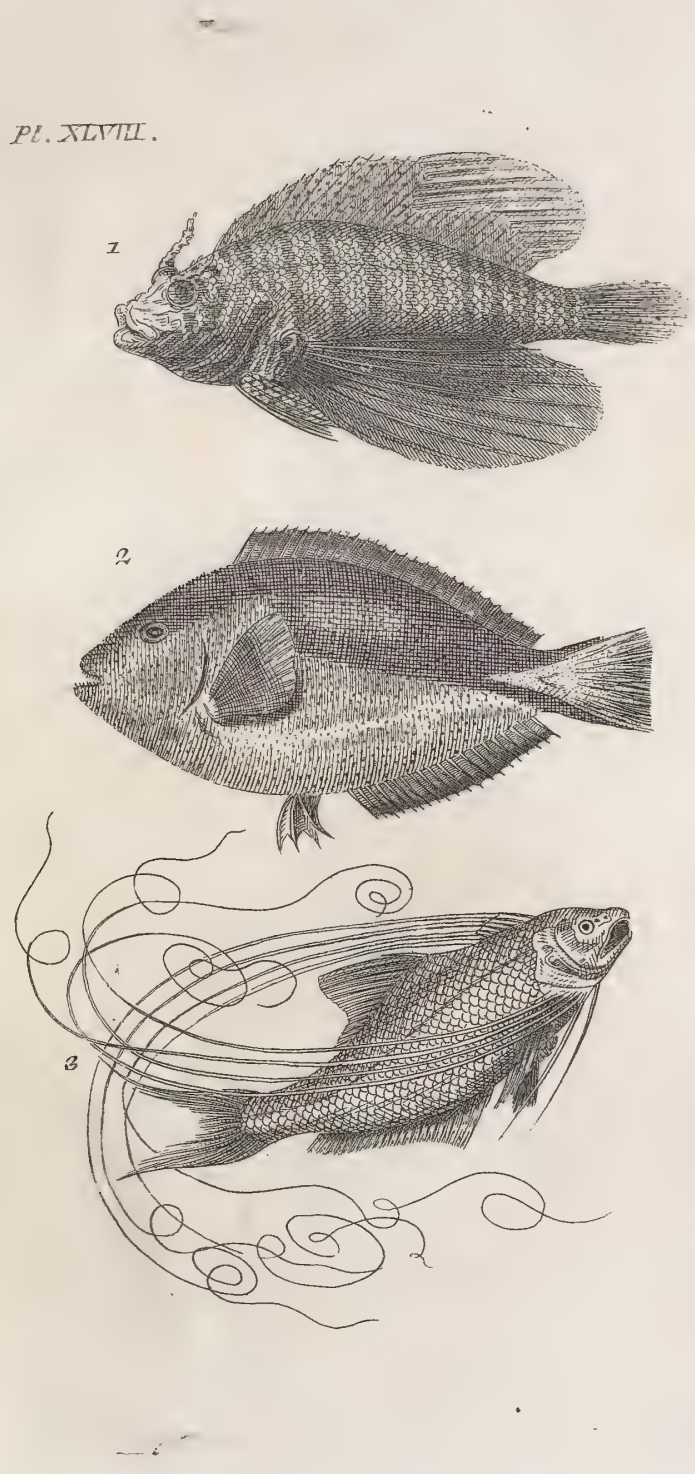




SMITHSONIAN INSTITUTION LIBRARIES 